\title{
Cas9/gRNA-mediated genome editing of yeast mitochondria and Chlamydomonas chloroplasts
}

\author{
Byung-Chun Yoo ${ }^{1}$, Narendra S Yadav ${ }^{1}$, Emil M Orozco, Jr. ${ }^{1}$, Hajime Sakai ${ }^{\text {Corresp. } 1}$ \\ 1 NAPIGEN, INC., Wilmington, Delaware, United States \\ Corresponding Author: Hajime Sakai \\ Email address: hajime.sakai@napigen.com
}

We present a new approach to edit both mitochondrial and chloroplast genomes. Organelles have been considered off-limits to CRISPR due to their impermeability to most RNA and DNA. This has prevented applications of Cas9/gRNA mediated genome editing in organelles while the tool has been widely used for engineering of nuclear DNA in a number of organisms in the last several years. To overcome the hurdle, we designed a new approach to enable organelle genome editing. The plasmids, designated "Edit Plasmids", were constructed with two expression cassettes, one for the expression of Cas9, codonoptimized for each organelle, under promoters specific to each organelle, and the other cassette for the expression of guide RNAs under another set of promoters specific to each organelle. In addition, Edit Plasmids were designed to carry the donor DNA for integration between two double-strand break sites induced by Cas9/gRNAs. Each donor DNA was flanked by the regions homologous to both ends of the integration site that were short enough to minimize spontaneous recombination events. Furthermore, the donor DNA was so modified that it did not carry functional gRNA target sites, allowing the stability of the integrated DNA without being excised by further Cas9/gRNAs activity. Edit Plasmids were introduced into organelles through microprojectile transformation. We confirmed donor DNA insertion at the target sites facilitated by homologous recombination only in the presence of Cas9/gRNA activity in yeast mitochondria and Chlamydomonas chloroplasts. We also showed that Edit Plasmids persist and replicate in mitochondria autonomously for several dozens of generations in the presence of the wild-type genomes. Finally, we did not find insertions and/or deletions (INDELs) at one of the Cas9 cleavage sites in chloroplasts, which are otherwise hallmarks of Cas9/gRNA-mediated NHEJ repair events in nuclear DNA. This is consistent with previous reports of the lack of NHEJ repair system in most bacteria, which are believed to be ancestors of organelles. This is the first demonstration of CRISPR-mediated genome editing in both mitochondria and chloroplasts in two distantly related organisms. The Edit Plasmid approach is expected to open the door to engineer organelle genomes of a wide range of organisms in a precise fashion. 


\section{Cas9/gRNA-mediated Genome Editing of Yeast}

\section{Mitochondria and Chlamydomonas Chloroplasts}

3

4 Byung-Chun Yoo, Narendra S. Yadav, Emil M. Orozco, Jr., and Hajime Sakai

5

6 Napigen, Inc., Wilmington, DE, USA

7

8

9

10

11 Corresponding Author:

12 Hajime Sakai

13 Napigen, Inc., Delaware Innovation Space, 200 Powder Mill Road, Wilmington, DE 19803,

14 USA

15 Email address: Hajime.Sakai@napigen.com 
18

19

20

21

22

23

24

25

26

27

28

29

30

31

32

33

34

35

36

37

38

39

40

41

42

43

44

45

46

47

48

\section{ABSTRACT}

We present a new approach to edit both mitochondrial and chloroplast genomes. Organelles have been considered off-limits to CRISPR due to their impermeability to most RNA and DNA. This has prevented applications of Cas9/gRNA mediated genome editing in organelles while the tool has been widely used for engineering of nuclear DNA in a number of organisms in the last several years. To overcome the hurdle, we designed a new approach to enable organelle genome editing. The plasmids, designated "Edit Plasmids", were constructed with two expression cassettes, one for the expression of Cas9, codon-optimized for each organelle, under promoters specific to each organelle, and the other cassette for the expression of guide RNAs under another set of promoters specific to each organelle. In addition, Edit Plasmids were designed to carry the donor DNA for integration between two double-strand break sites induced by Cas9/gRNAs.

Each donor DNA was flanked by the regions homologous to both ends of the integration site that were short enough to minimize spontaneous recombination events. Furthermore, the donor DNA was so modified that it did not carry functional gRNA target sites, allowing the stability of the integrated DNA without being excised by further Cas9/gRNAs activity. Edit Plasmids were introduced into organelles through microprojectile transformation. We confirmed donor DNA insertion at the target sites facilitated by homologous recombination only in the presence of Cas9/gRNA activity in yeast mitochondria and Chlamydomonas chloroplasts. We also showed that Edit Plasmids persist and replicate in mitochondria autonomously for several dozens of generations in the presence of the wild-type genomes. Finally, we did not find insertions and/or deletions (INDELs) at one of the Cas9 cleavage sites in chloroplasts, which are otherwise hallmarks of Cas9/gRNA-mediated NHEJ repair events in nuclear DNA. This is consistent with previous reports of the lack of NHEJ repair system in most bacteria, which are believed to be ancestors of organelles. This is the first demonstration of CRISPR-mediated genome editing in both mitochondria and chloroplasts in two distantly related organisms. The Edit Plasmid approach is expected to open the door to engineer organelle genomes of a wide range of organisms in a precise fashion.

\section{INTRODUCTION}

Organelles, such as mitochondria and chloroplasts, are cellular components of eukaryotic cells. They serve as sites of specific cellular functions: Mitochondria are the sites for respiration, 
49 producing most of the cellular energy, ATP and NADH, while chloroplasts are primarily the sites

50 for photosynthesis, converting light energy into cellular energy and sugar compounds in

51 photosynthetic eukaryotes. Organelles also play an important role in metabolism, producing a

52 number of key metabolites through their unique biochemical pathways such as TCA cycle, fatty

53 acid $\beta$-oxidation and Calvin cycle.

54 For biotechnology applications, they also offer the potential as novel production platforms in 55 eukaryotic cells. They are already sites for the biosynthesis of several valuable metabolites (e.g., 56 amino acids, lipids, nucleic acids), including secondary metabolites related to nutraceutical and 57 pharmaceutical compounds (Almaraz-Delgado et al., 2014; Nielsen et al, 2016). Furthermore, 58 organelles provide efficiency in pathway engineering since the metabolic intermediates can be 59 better channeled into desirable products without dilution with the larger pool of cytoplasmic 60 metabolites (Viitanen et al., 2004; Avalos, Fink \& Stephanopoulus, 2013; Jin \& Daniell, 2015).

61 Mitochondria and chloroplasts have their own genomes. Organelle DNA provides a particular 62 advantage because it can allow very high transgene expression through high copy number, as 63 each cell can contain over 1000 copies of organelle DNA (Morley \& Nielsen, 2016). A typical 64 plant leaf cell can contain up to 1,000 - 2,000 copies of the plastid DNA. This copy number 65 advantage has already been exploited in plant chloroplasts, where a heterologous protein 66 comprised up to $70 \%$ of leaf soluble cell protein in a plastid transgenic line in tobacco (Oey et 67 al., 2009).

68 Because of the importance of organelles, several key technologies have been developed to 69 allow manipulation of organelle DNA in the past. Examples include DNA transformation in 70 yeast mitochondria (Fox, Sanford \& McMullin, 1988), Chlamydomonas and higher plant chloroplasts (Boynton et al., 1988; Syab et al., 1990), as well as high protein expression in tobacco chloroplasts (McBride et al., 1995). Manipulations of organelle DNA in the past have relied on the integration of engineered DNA into the organelle genomes through homologous recombination and subsequent selection of transgenic DNA by selectable markers, such as the aadA gene that confers resistance to spectinomycin.

While the activity of homologous recombination is relatively high in organelles, it is desirable 77 to have a tool like CRISPR to allow precise genome manipulations. Such a tool will be useful 78 for applications like gene therapy for treatment of human diseases caused by mitochondrial 79 mutations (Leslie, 2018) and for engineering traits of crop plants such as biotic/abiotic stress 
80 tolerance, better $\mathrm{CO}_{2}$ fixation and better yield by hybridization through altering organelle

81 functions (Ishiga et al., 2017; Estavillo et al., 2011; Cummins, Kannappan \& Gready, 2018;

82 Hanson \& Bentolila, 2004). Such applications in agriculture are widely considered non-GMO

83 (Jaganathan et al., 2018). Nevertheless, unlike nuclear genomes, organelle genomes haven't

84 received much attention from the recent applications of genome editing technologies due to the

85 double membranes that enclose the organelles and prevent the import of most nucleic acids

86 (Leslie, 2018). Since CRISPR requires guide RNA and, in some cases, template DNA for donor

87 DNA insertion at target sites in addition to Cas9-type endonuclease protein, such barriers are

88 crucial obstacles for the application of the advanced genome editing approach in organelles.

89 This would reflect few successful attempts were reported with regard to CRISPR on organelle

90 DNA in the past, while numerous successful applications on nuclear DNA have been published

91 in the last several years. One such rare report describes a reduced amount of the mitochondrial

92 gene that was targeted by simple overexpression of Cas9/guide RNA in the cytoplasm of human

93 cells (Jo et al., 2015). However, it lacks any molecular evidence of cleavages induced by

94 CRISPR to support their findings. In addition, donor DNA insertion at target sites will not be 95 possible through such an approach because of the difficulty in importing template DNA into 96 mitochondria.

97 To overcome the difficulty of organelle genome editing, we developed a new approach of 98 organelle genome engineering for the deployment of the CRISPR system. Our approach utilizes plasmids ("Edit Plasmids") that are designed to replicate autonomously in organelles. A typical Edit Plasmid carries a cassette for the organelle-specific expression of Cas9-type endonuclease, a cassette for the expression of guide RNA(s), donor DNA, and a selectable or screenable marker. As a proof of concept, we designed and constructed prototypic versions of Edit Plasmids and introduced them into mitochondria of the yeast, Saccharomyces cerevisiae, and chloroplasts of the alga, Chlamydomonas reinhardtii, using microprojectile-based transformation. In both experimental systems, we found successful donor DNA insertion in both experimental systems only when Cas9/gRNA were present in the Edit Plasmids. In addition, we analyzed DNA sequence at a gRNA target site in transgenic C. reinhardtii chloroplasts. We did not find Cas9dependent SNPs or INDELs, which are usually hallmarks of nuclear genome editing through NHEJ DNA repair processes. As an evidence of autonomous replication, we were also able to rescue the Edit Plasmid from yeast cells that were grown for more than 20 generations after the 
111 cross between two strains carrying the Edit Plasmid and the wild-type mitochondrial genome.

112 Our results demonstrate the Edit Plasmids represent effective tools for organelle genome editing 113 and writing overall.

114

115 MATERIALS \& METHODS

116 Cell cultures and chloroplast transformation in Chlamydomonas reinhardtii

117 The wild-type line of Chlamydomonas reinhardtii (CC-125) was obtained from the

118 Chlamydomonas Resource Center (www.chlamycollection.org, University of Minnesota, St.

119 Paul, MN). Edit Plasmids were transformed into CC-125 using PDS-1000He particle delivery

120 system (Bio-Rad) according to the methods described in Barrera, Gimpel \& Mayfield (2014) and

121 Ramesh, Bingham \& Webber (2011). Chloroplast transformants were selected on the Tris-

122 Acetate-Phosphate (TAP) media supplemented with $100 \mu \mathrm{g} / \mathrm{ml}$ of spectinomycin under the light

123 intensity of $50 \mu \mathrm{mol} / \mathrm{m}^{2} \mathrm{~s}$. The TAP media were made as described at the above-mentioned

124 website of the Chlamydomonas Resource Center.

125

126

\section{Design of sgRNAs for Chlamydomonas chloroplast DNA}

127 Guide RNA target sites were selected in the psaA gene (Gene ID: 2717000) encoded in the

128 chloroplast genome of Chlamydomonas reinhardtii (NCBI accession: NC_005353). The psaA

129 gene encodes Photosystem I P700 chlorophyll a apoprotein A1, involved in photosynthesis and

130 essential for photoautotrophic growth (https://www.uniprot.org/uniprot/P12154). To help design

131 and select guide RNA target sites, a web-based Bioinformatics program, CRISPOR

132 (http://crispor.tefor.net/; Haeussler et al., 2016) was employed. The gRNA targeting sequences

133 chosen were all in exon 4 of the $p s a A$ gene: 5'GGTTTAAACCCTGTTACTGGTGG3'

134 (sgRNA1c), 5'CTTCACCTGTAAATGGACCACGG3' (sgRNA2c),

135 5'TTTACAGGTGAAGGTCACGTTGG3' (sgRNA3c), and

136 5'GTAGCTAAATAAGGGTATGGAGG3' (sgRNA4c) with last 3 nucleotides as PAM

137 sequences. These sgRNAs were fused with tracrRNA sequence,

138 5'GTTTTAGAGCTAGAAATAGCAAGTTAAAATAAGGCTAGTCCGTTATCAACTTGAA

139 AAAGTGGCACCGAGTCGGTGCT3', to form functional guide RNAs.

Construction of chloroplast genome-editing vectors 
142 For gene expression in chloroplasts, we used the promoters and 5'-untranslated regions of 143 following genes encoded in the Chlamydomonas chloroplast genome; $r b c L$ (Franklin et al., 144 2002), psaA (Young \& Purton, 2014), and psbD (Kasai et al., 2003). For terminators of 145 transcription, we used 3'-untranslated regions of the Chlamydomonas chloroplast genes, $p s b A$ 146 (Noor-Mohammadi, Pourmir \& Johannes, 2012) and $r b c L$ (Young \& Purton, 2014).

147 For the expression of the selectable marker, aadA gene, we used the $r b c L$ promoter with its 5, 148 UTR, and a $p s b A 3^{\prime}$ ' UTR. The expression cassette was synthesized in three parts by GenScript. 149 Synthesized DNA fragments were assembled using a strategy involving Type IIS restriction 150 enzyme, BsaI, (Bertalan et al., 2015) and ligated into pBR322 that had been digested with

151

152 153 154 155 156 157 158 159 160

161

162 163 164 165 166 167 168 169 HindIII and $A v a \mathrm{I}$ to create the pBR322-aadA intermediate vector. The aadA cassette was then transferred to pUC19, resulting in YP4 (chloroplast Edit Plasmids are listed with the information on their core components in Table 1).

The Cas9 endonuclease gene derived from Streptococcus pyogenes (SpCas9) was codonoptimized using the Codon Usage Database (https://www.kazusa.or.jp/codon/; Nakamura, Gojobori \& Ikemura, 2000) in combination with manual editing to reduce long mononucleotide repeats (see Figure $\mathrm{S} 1$ ). The Cas9 expression cassette was composed with the psaA-exon 1 promoter with its 5' UTR, the codon-optimized Cas9 (Cas9c) and $r b c L$ 3' UTR. The components were synthesized at GenScript, assembled using BsaI and ligated into YP4. The resulting plasmids, YP5, was used to construct an Edit Plasmid YP11 carrying a cassette for the expression of double sgRNAs.

The sgRNA cassette contained the following elements in 5' to 3' orientation: The $102 \mathrm{bp}$-long promoter of tRNA ${ }^{\operatorname{Trp}}(\mathrm{CCA}), \mathrm{tRNA}^{\mathrm{Trp}}(\mathrm{CCA}), \mathrm{sgRNA}^{\mathrm{sgRNA}} \mathrm{sc}$ ), tRNA ${ }^{\mathrm{Lys}}$ (UUU), sgRNA (sgRNA2c), tRNA ${ }^{\text {Leu }}(\mathrm{UAG})$ and 101 bp-long terminator of tRNA ${ }^{\text {Trp }}(\mathrm{CCA})$. The second sgRNA cassette with sgRNA (sgRNA3c) and sgRNA ( $\operatorname{sgRNA} 4 \mathrm{c})$ was created with the same elements by DNA synthesis followed by BsaI digestion and ligation with YP5 that was digested by BglII and AgeI. This resulted in the YP12 construct.

Next, the donor DNA fragment was synthesized with the GFP gene (GFPc) optimized for the Chlamydomonas codon usage (Franklin et al. 2002) that was flanked with the sequences homologous to the Cas9 cleavage sites created by the pair of guide RNAs encoded in each construct. Those homologous sequences consisted of 74 bp (HR1) or 76 bp (HR2, HR3, HR4) in 
172 length. The synthesized donor fragments were ligated into YP11 and YP12, resulting in YP13 173 and YP14, respectively.

174 Another set of Edit Plasmids (YP6, YP19, YP20, YP21, YP22) was constructed similarly with 175 the Cas9 expression cassette that consisted of the $p s b D$ promoter and its 5' UTR instead of the 176 psaA-exon 1 promoter with its 5' UTR. Negative control plasmids YP23 and YP24 were 177 constructed from YP13 and YP14, respectively, by removing the Cas9 expression cassette with 178 EcoRI and HindIII digestion and filling in, followed by ligation. Furthermore, constructs with 179 the pBR322 backbone were made as follows: YP31, by ligating the AvrII - NheI fragment from 180 YP11 and NheI digested pBR322-aadA plasmid; YP33, by ligating the AvrII - NheI fragment 181 from YP19 and NheI digested pBR322-aadA plasmid; YP29, by ligating the AgeI - NheI 182 fragment from YP23 and AgeI/NheI-digested pBR322-aadA plasmid.

183

\section{Analysis of donor DNA insertion at Cas9 target sites in Chlamydomonas chloroplasts}

For PCR analysis of Cas9/gRNA-mediated donor DNA insertions in Chlamydomonas

chloroplast, cell lysates were prepared from each individual transformant that was grown on TAP/spectinomycin $(100 \mu \mathrm{g} / \mathrm{ml})$ medium, following the protocol described in Barrera, Gimpel \& Mayfield (2014). Cell lysates were pooled per construct and subjected to PCR reactions where each reaction in $25 \mu \mathrm{l}$ consisted of $2 \mu \mathrm{l}$ of pooled cell lysates as a template and $2 \mathrm{X}$ master mix Q5 high-fidelity polymerase (New England Biolabs). The primers used for PCR amplification were C1 (5'GCTGGTTGGTTCCACTACCAC 3'), C2

192 (5'CATACGGTGTACAATGTTTCAGTCG 3'), C3

193 (5'CACCTTCAAATTTTACTTCAGCACGTG 3'), and C4

194 (5'GTGAGAAATAATAGCATCACGGTGAC 3'). C1 and C4 primers recognized the region of 195 the Chlamydomonas chloroplast genome in the vicinity of the designed Cas9/gRNA cleavage 196 sites. C2 and C3 are specific for the donor DNA. The pairs C1-C3 and C2-C4 were used for the 197 amplification of the genomic region replaced with the donor DNA, including the junction regions. The PCR amplification was performed as follows: Initial denaturation, $98^{\circ} \mathrm{C}$ for $30 \mathrm{sec}$; 35 cycles of $98^{\circ} \mathrm{C}$ for $10 \mathrm{sec}, 56^{\circ} \mathrm{C}$ for $20 \mathrm{sec}$, and $72^{\circ} \mathrm{C}$ for $1 \mathrm{~min}$; final polymerization $72^{\circ} \mathrm{C}$ for 2 min. Aliquots of PCR reaction were analyzed on agarose gels. Amplified DNAs were purified using Qiagen PCR Purification kit and subjected to direct sequencing at GENEWIZ, LLC. DNA 
202 sequencing analysis was performed by using Vector NTI ContigExpress software (Thermo 203 Fisher Scientific).

204

205

206

207

208

209

210

211

212

213

214

215

216

217

218

219

220

221

222

223

224

225

226

227

228

229

230

231

232

\section{Characterization of on-target mutations at Cas9 target site in Chlamydomonas chloroplasts}

Sequence variations created by Cas $9 /$ gRNA activity was analyzed at the AvaII recognition site (GGWCC) present within one of the Cas9 target sites, sgRNA2c

(5'CTTCACCTGTAAATGGACCACGG3' PAM sequence in bold).

First, cell lysate was extracted from individual colonies transformed with each construct as described above. The numbers of colonies assayed in this experiment were 10 for YP5 (control), 15 for YP11, 5 for YP29 (control), 10 for YP31, and 7 for YP33 (Step 1). We then made cell lysates from pooled five colonies derived from independent transformation events except for YP33 with seven colonies. Pooled DNA samples were subjected to the amplification of the genomic region containing the target site using the $\mathrm{Q} 5^{\circledR}$ high-fidelity polymerase-based PCR amplification system (New England Biolabs) and the primer set, $\mathrm{C} 1$ and $\mathrm{C} 4$ (see above). The PCR reaction was conditioned as follows: Initial denaturation, $98^{\circ} \mathrm{C}$ for $30 \mathrm{sec} ; 35$ cycles of $98^{\circ} \mathrm{C}$ for $10 \mathrm{sec}, 60^{\circ} \mathrm{C}$ for $20 \mathrm{sec}$, and $72^{\circ} \mathrm{C}$ for $30 \mathrm{sec}$; final polymerization $72^{\circ} \mathrm{C}$ for $2 \min$ (Step 2). Amplified DNA products were purified using DNA Clean \& Concentrator 5 (Zymo Research) and subjected to AvaII digestion overnight (Step 3). After gel electrophoresis, the region corresponding to $700-900 \mathrm{bp}$ of each pool, containing undigested DNA of $795 \mathrm{bp}$, was cut out of agarose gel and the DNA was extracted using QIAquick Gel Extraction Kit (Qiagen) (Step 4). Extracted DNA was then directly cloned into pMiniT2.0 vector according to a manufacturer's protocol (New England BioLabs) (Step 5). We randomly selected twelve E. coli colonies from each pool of transformants with positive constructs (YP11, YP31 and YP33) and eight colonies from the pools with control constructs YP5 and YP29, and performed PCR amplification using the primer pair, $\mathrm{C} 1$ and $\mathrm{C} 4$ (Step 6). Aliquots of PCR reactions were digested with AvaII and analyzed by electrophoresis to narrow down the candidates for altered AvaII sites through sequencing analysis (Step 7). If a rare DNA editing event occurred, AvaII restriction site is likely to be lost, and, thus, AvaII digestion would enrich for such events. Selected clones were one from YP5, two from YP11, five from YP31 and three from the YP29 transformants. PCR amplicons were purified and subjected to Sanger-sequencing and analyzed using Vector NTI ContigExpress program (Step 8). In addition, we randomly selected multiple colonies from Step 
233 5, isolated DNA using QIAprep Spin Miniprep kit (Qiagen), sequenced at GENEWIZ, LLC and 234 analyzed for any change in the AvaII sequence.

235

236

Strains, media and genetic methods for yeast

237 The yeast strains used in this study are listed in Table 2. Minimal media and standard genetic

238 methods were described in Sherman, Fink \& Hicks (1986) unless otherwise specified below.

239

240 Design of sgRNAs for yeast mitochondrial DNA

241 Guide RNA target sites were selected from the COX1 gene (Gene ID: 854598) in the

242 mitochondrial genome of Saccharomyces cerevisiae S288c (NCBI accession: NC_001224). The

$243 C O X 1$ gene encodes cytochrome $\mathrm{C}$ oxidase subunit I that is part of the respiratory electron

244 transport chain in all eukaryotes and is required in yeast for growth on non-fermentable carbon

245 source (https://www.yeastgenome.org/locus/S000007260). To help design and select guide RNA

246 target sites, a web-based Bioinformatics program, CRISPOR (http://crispor.tefor.net/, Haeussler

247 et al., 2016) was employed. The unique gRNA targeting sequences chosen for the COX1 gene

248 were 5'TTCTTTGAAGTATCAGGAGGTGG3' (sgRNA1m) and 5'

249 ATGATTATTGCAATTCCAACAGG 3' (sgRNA2m) with the last 3 nucleotides (bold letters)

250 as PAM sequences. Each of guide RNA target site without PAM sequence was fused with

251 tracrRNA to create functional single guide RNAs. The tracrRNA sequence used was:

252 5'GTTTTAGAGCTAGAAATAGCAAGTTAAAATAAGGCTAGTCCGTTATCAACTTGAA

253 AAAGTGGCACCGAGTCGGTGCT3'.

254

255 Construction of mitochondrial genome-editing vectors

256 For the construction of Edit Plasmids to test in yeast mitochondria, pHD6 (Green-Willms et al.

257 2001) was modified as follows. First, pHD6 was digested with PstI and HindIII to remove

258 previously cloned fragments except for the following: $0.75 \mathrm{~kb} C O X 3$ gene fragment pBR322-

259 based replication ori and $a m p^{R}$. Then, following elements were inserted: Cas 9 expression

260 cassette, sgRNA expression cassette, and donor DNA. The sequence encoding Cas9 was codon-

261 optimized for expression in yeast mitochondria (Figure S2). In addition, six tryptophan codons

262 (TGG) at positions W18, W464, W659, W883, W1074, and W1126 of the 1366 aa Cas9 protein

263 were changed to TGA, which codes for tryptophan in mitochondria but for a translational stop in 
264 the cytoplasm to avoid any Cas9 expression outside of mitochondria. Codon-optimized Cas9 265 gene (Cas9m) was synthesized along with the $71 \mathrm{bp}$-long minimal promoter and the $119 \mathrm{bp}$-long 266 terminator of the COX2 gene (Mireau, Arnal \& Fox, 2003), and was flanked with PstI and 267 HindIII sites (GenScript). A multicloning locus with XbaI, NotI and NcoI sites was also added 5' 268 end of the HindIII site to facilitate subsequent subcloning of other cassettes.

269 The sgRNA expression cassette contained the following in 5' to 3' orientation: a 75 bp 270 minimal $C O X 3$ promoter consisting of the TATA box, transcription initiation site and 5'UTR; 271 tRNA ${ }^{\text {Phe }}$ (GAA); sgRNA2m; a tRNA ${ }^{\text {Trp }}$ (UGA); sgRNA1m; tRNA ${ }^{\text {Met }}$ (CAU) and a 118 bp 272 minimal $C O X 3$ terminator including the dodecamer (Turk et al., 2013). The sgRNA expression 273 cassettes were synthesized with a NotI site at the 5' end and a NcoI site at the 3' end to allow 274 directional cloning in the Edit Plasmid and maintain the direction of transcription of the Cas9 275 and guide RNA cassettes same on the resulting plasmids.

276 To construct HS8, the donor DNA carrying the GFP gene was synthesized and cloned into the 277 NcoI site of the plasmid that contained Cas9 and guide RNA expression cassettes. The 278 nucleotide sequence encoding GFP was codon-optimized for expression in yeast mitochondria 279 (Cohen and Fox, 2001). A tryptophan codon corresponding to W57 was changed to TGA, 280 assuring GFP expression only in mitochondria. The GFP coding region (GFPm) was fused in281 frame with the $C O X 1 \mathrm{ORF}$ at the sgRNA1m cleavage site by adding the following linker 282 sequence between COX1 ORF (italic lowercase) and GFPm ORF (underlined lowercase): 283 tttcggagtttctggtggaggTGGTGGAatgacacat. Both ends of the GFPm ORF were fused with the $284 C O X 1$ genomic sequences external to the Cas9 cleavage sites to allow homology-directed 285 recombination: $144 \mathrm{bp}$ adjacent to the sgRNA1m site (HR1m) and 115 bp adjacent to the 286 sgRNA2m site (HR2m). Furthermore, the guide RNA recognition sites within the donor DNA was modified to prevent subsequent cleavages by Cas9: The sgRNA1m sequence was changed at 288 7 out of the 23 nucleotides without altering the encoded amino acid sequence as follows: TTCTTTGAAGTATCAGGAGGTGG (original) to TTTTTCGGAGTTTCTGGTGGAGG (modified nucleotides in donor DNA in bold). The sgRNA2m sequence was modified by deleting 16 nucleotides at the 5' end of the recognition site as follows: 
294

295

296

297

298

299

300

301

302

303

304

305

306

307

308

309

310

311

312

313

314

315

316

317

318

319

320

321

322

323

324

The control constructs HS6 was created by deleting the Cas9 expression cassette from HS8 through the digestion with PstI and NotI, followed by electrophoresis and elution of 5.5kb DNA, and the ligation with the linker (5'GAAGATCTAACCGCGGAAGC3' and 5'GGCCGCTTCCGCGGTTAGATCTTCTGCA3').

\section{Yeast mitochondrial transformation}

The constructs were transformed into a yeast line that lacked mitochondrial DNA $\left(r h o^{0}\right)$, MCC109rho ${ }^{0}$, using the biolistic microprojectile method as described in Bonnefoy and Fox, 2007. The transformation was performed together with pYES2 (Invitrogen) as a carrier plasmid with $U R A 3$ selectable marker, so that $\mathrm{URA}^{+}$nuclear transformants could be selected first on minimal medium lacking uracil in supplements. To identify mitochondrial transformants, $\mathrm{URA}^{+}$ colonies were assayed for the ability to rescue the cox3 deletion mutation of the $r h o^{+}$line, MCC125, after the cross. The URA ${ }^{+}$transformants that carried Edit Plasmids in mitochondria through co-transformation events were able to provide the wild-type $C O X 3$ fragment to rescue the cox3 deletion by homologous recombination. The screen was repeated three times to obtain clean lines with Edit Plasmids in mitochondria. To analyze the Cas9 activity of the Edit Plasmids, five isolated lines containing each of Edit Plasmids and the line containing the wildtype mitochondrial genome, CUY563, were activated in YPD medium overnight and crossed together by mixing an aliquot of cells on the SD medium supplemented with adenine and uracil and incubating at $30^{\circ} \mathrm{C}$. Under the condition, transformant and diploid cells could grow but not CUY563, facilitating the cytoplasmic fusion of two strains in the presence of the kar1-1 mutation, which prevents nuclear fusion and stable diploidization (Conde \& Fink, 1976). After 48 hours of incubation, cells were suspended in $300 \mu \mathrm{H}_{2} \mathrm{O}$ and concentrated through centrifugation under $3,000 \mathrm{xg}$ for five minutes and resuspension in $50 \mu 1 \mathrm{H}_{2} \mathrm{O}$. $1 \mu \mathrm{l}$ of cells was subjected to the analysis of the genome editing effect by Cas 9 at the target sites.

\section{Analysis of donor DNA insertion between two Cas9 target sites and plasmid stability in} yeast mitochondria

To detect the presence of the donor DNA inserted between two Cas9 target sites in the mitochondrial genome, two primer sets, $\mathrm{C}-12$ and F-11, were designed to amplify the junction regions: The Primer C (5'CTATTCAGGCACATTCAGGACC3') recognizing the genomic 
325 region 250 bp upstream of the sgRNA1m site and Primer 12

326 (5'GATCTGCTAATTGTACTGAACCG3') recognizing the donor DNA 560 bp downstream of 327 the sgRNA1m site, and the Primer 11 (5'CAGGTGAAGGTGAAGGTGATGC3') recognizing 328 the donor DNA 610 bp upstream of the sgRNA2m site and Primer F

329 (5'AGAGGTATACCAACACAAGATTC3') recognizing the genomic region $260 \mathrm{bp}$ 330 downstream of the sgRNA2m site. For the PCR amplification, $1 \mu 1$ of cell suspension prepared

331

332 333

334

335 336

337

338 339

340

341

342

343

344

345

346

347

348

349

350

351

352

353

354

355 as described above was used for one $25 \mu 1$ PCR reaction with One-Taq Quick-Load 2X Master Mix (New England Biolabs) and $5 \mu \mathrm{M}$ of each primer. The PCR amplification was performed as follows: 1) $7 \mathrm{~min}$ at $\left.94^{\circ} \mathrm{C}, 2\right) 30 \mathrm{sec}$ at $\left.94^{\circ} \mathrm{C}, 3\right) 30 \mathrm{sec}$ at $\left.52^{\circ} \mathrm{C}, 4\right) 1 \mathrm{~min} 30 \mathrm{sec}$ at $\left.60^{\circ} \mathrm{C}, 5\right)$ go to step 2 for 39 times, 6) $10 \mathrm{~min}$ at $60^{\circ} \mathrm{C}$. The PCR products were separated on $1.2 \%$ agarose gel by electrophoresis. The DNA bands that corresponded to the junction fragments were cut out of the gel and subjected to the DNA extraction using the QIAquick Gel Extraction Kit (Qiagen). The eluted DNA samples were sequenced with Primers C, F, 11 and 12 at GENEWIZ, LLC. Vector NTI and SnapGene were used for DNA sequence analyses.

For the analysis of the plasmid stability in yeast mitochondria, the yeast cultures were created as described above with the modification of using the wild-type strain NB80 instead of CUY563 for the cross with the MCC $109 r h o^{0}$ line carrying HS8. The cultures of crossed cells in SD minimal medium were further advanced to the third and fourth overnight culture. Cells were sampled from each culture as described above. The PCR amplification was performed with a primer set, G and 12: Primer G (5'GAGAACAAATGGTATGACAATGCAT3') recognizing the donor DNA and Primer 12 (see above). The condition of PCR reaction was same as above.

\section{Rescue of plasmids from yeast mitochondria transformants}

For the rescue of Edit Plasmids from yeast cells, $1 \mathrm{ml}$ of the second overnight cell culture was sampled and total DNA isolated using the Quick-DNA Miniprep Plus Kit (Zymo Research). 200 ng of isolated total DNA was digested with ApaI and SphI to cleave pYES2 plasmid DNA in the total DNA fraction, while the HS8 plasmid remained intact as it lacked these restriction sites. After inactivating the restriction enzymes at $65^{\circ} \mathrm{C}$ for $20 \mathrm{~min}$, the DNA was transformed into E.coli using the Stable competent cells (New England Biolabs). Colonies that grew on LB medium containing carbenicillin were subjected to plasmid DNA isolation. Plasmid DNA was 
356 then subjected to the digestion with several restriction enzymes, and the digestion products were

357 analyzed by gel electrophoresis.

358

359 RESULTS

\section{Edit Plasmid design strategy for Chlamydomonas chloroplasts}

361 The Edit Plasmids used in the transformation of Chlamydomonas chloroplasts were designed and

362 constructed as follows (Figure $1 \&$ Table 1). First, we used either pBR322 or pUC19 for the

363 vector backbone with pMB1 replication origin previously reported to replicate in chloroplasts

364 (Boynton et al., 1988). Second, we optimized the codons of the Cas9 gene derived from

365 Streptococcus pyogenes for Chlamydomonas chloroplast expression without altering the amino

366 acid sequence and without adding any chloroplast transit peptide sequence or nuclear localization

367 signal sequence (Figure S1). Third, a strong promoter, psaA promoter and its 5' UTR, and a

368 weaker promoter, $p s b D$ promoter and its 5' UTR, from the Chlamydomonas chloroplast genome

369 (Michelet et al., 2011), were used to express the codon-optimized Cas9 gene. Fourth, four guide

370 RNA sites were selected from the exon 3 of the $p s a A$ gene to have unique targets in the

371 Chlamydomonas chloroplast genome (see MATERIALS and METHODS). Fifth, to generate

372 correctly processed gRNAs, tRNA processing scheme was employed as shown by Xie,

373 Minkenberg \& Yang (2015) with the following modification: Instead of using nuclear RNA

374 polymerase III promoter as described in Xie, Minkenberg \& Yang (2015) and Cong et al. (2013),

375 we utilized the promoter of tRNA ${ }^{\operatorname{Trp}}$ (CCA) gene from the Chlamydomonas plastid for the

376 expression of guide RNAs. To have proper processing of sgRNAs following their transcription

377 in chloroplasts, a multiplex sgRNA configuration was designed; tRNA-1 - sgRNA-1 - tRNA-2 -

378 sgRNA-2 - tRNA-3. The tRNA genes of Chlamydomonas plastids used for the proper

379 processing were: tRNA ${ }^{\text {Trp }}$ (CCA) for tRNA-1, tRNA ${ }^{\text {Lys }}$ (UUU) for tRNA-2, and tRNA ${ }^{\text {Leu }}$ (UAG)

380 for tRNA-3. Sixth, a donor DNA was designed with the GFPc gene that had been optimized for

381 the expression in Chlamydomonas chloroplasts (Franklin et al., 2002). For homologous

382 recombination of the donor DNA at the sites cleaved by Cas9/double gRNAs, the ends of the

383 donor DNA were fused with the genomic sequence at the cleavage sites in the exon 3 of the psaA

384 gene. To preclude additional cleavages by Cas9 and guide RNAs after replacement, HR

385 sequences contained silent mutations at the gRNA target sites such as removing of PAM

386 sequence (see MATERIALS and METHODS). In addition, homologous recombination was 
387 designed to give an in-frame fusion of GFPc with the $p s a A$ gene product. Seventh, the aadA 388 selectable marker was present on the Edit Plasmids constructs to allow positive selection of the 389 plasmids. The promoter and terminator for the expression of selectable marker were the $r b c L$ 390 promoter with its 5' UTR and the $p s b A$ 3' UTR, respectively.

391

392

393

Cas9/gRNA-driven donor DNA insertion between two Cas9 target sites in Chlamydomonas chloroplasts

395

396

397

398

399

400

401

402

403

404

405

406

407

408

409

410

411

412

413

414

415

416

417

To assess donor DNA insertion mediated by Cas9/gRNA in Chlamydomonas chloroplasts, the wild-type strain of Chlamydomonas reinhardtii, CC-125, was transformed with the following Edit Plasmids, YP13, YP14, YP21, or YP22 (see MATERIALS and METHODS, Table 1).

These plasmids were designed to evaluate an optimal promoter strength for Cas9 expression and to compare the efficacy of gRNAs ( $\operatorname{sgRNA} 1 \mathrm{c}-\mathrm{sgRNA} 2 \mathrm{c}$ vs $\mathrm{sgRNA3} \mathrm{c}-\mathrm{sgRNA} 4 \mathrm{c}$ ). Promoters used were a strong promoter ( $p s a A$ promoter with its $5^{\prime}$ UTR) and a weaker promoter ( $p s b D$ promoter with its 5' UTR). In addition, two negative control plasmids, YP23 and YP24, carrying two gRNAs and donor DNA but no Cas9, were included to assess the background frequency of spontaneous homologous recombination.

For the screening of Cas9-mediated donor DNA insertion events among transformants, we designed the PCR primer pairs which consisted of a primer specific to the chloroplast genome at the integration sites and a primer specific to GFPc (Figure 2A). The primer sets did not produce any DNA product after PCR amplification using the DNA from the wild-type strain as template (Figure 2B; lane 14).

Twenty eight days post transformation, cell lysates from 20 independent colonies of all constructs except for YP23 and YP24 with 16 colonies were prepared in pools. The lysates were used for analyzing the replacement events with donor DNA through PCR amplification using a primer pair $\mathrm{C} 2$ and $\mathrm{C} 4$ (see MATERIALS and METHODS). PCR screening showed that the expected sizes of the amplicon was only detected from the pools derived from YP13 transformants (Figure 2B, lanes $2 \& 3$ ), but not from other constructs including negative control constructs, YP23 and YP24, lacking the Cas9 expression cassette but having donor DNA as well as gRNAs (Figure 2B, lanes 10,11, $12 \& 13$; Table 3). This suggested that there was no detectable homologous recombination using Edit Plasmids containing donor DNA without Cas9 activity. This observation is consistent with the result observed by Dauvillee et al. (2004), 
418 showing that the lengths of the left and right homologous regions used in this experiment (74 and $41976 \mathrm{bp}$, respectively) were insufficient to induce homologous recombination in Chlamydomonas 420 chloroplasts effectively. Based on these control results, we conclude that the positive detection 421 of donor DNA insertion events in the YP13 construct was induced by Cas9/guide RNA activity. 422 YP13 contained two guide RNAs, gRNA1c and gRNA2c, and the strong psaA promoter with 423 its 5'UTR for the Cas9 expression. YP14 with different gRNAs, gRNA3c and gRNA4c, with 424 other components same as YP13 failed to detect replacement events (Figure 2B, lanes 4, 5, \& 6; 425 Table 3). This contrasting result showed the varying efficacy of designed guide RNAs. The 426 other contrasting result was observed in the strength of promoters driving Cas9. Edit Plasmid 427 YP21, in which Cas9 was expressed under the weaker promoter, $p s b D$ promoter in combination 428 with the efficacious gRNAs (gRNA1c and gRNA2c), did not yield any expected amplicon 429 (Figure 2B, lanes $7 \& 8$, Table 3).

430

Further PCR with individual cell lysates of positive pools of YP13 transformants was performed for de-convolution (Figure 2C). Two out of 12 transformants taken from the two 433 pools showed amplicons of the expected size using primer pair $\mathrm{C} 1 / \mathrm{C} 3$ as well as primer pair $\mathrm{C} 2 / \mathrm{C} 4$, representing the left and right junction fragments. Overall, the frequency of positive events was 2 out of 20 independent transformants (10\%) with the YP13 construct that contained the two guide RNAs, sgRNA1c and sgRNA2c, and Cas9 expressed by the strong psaA promoter. In experiments involving the other constructs that did not contain these elements, e.g., constructs with Cas9 expressed by the weak promoter, it was 0 out of 69 independent transformants $(0 \%)$ in total (see Table 3). The t-test of the data set gave p-value of 0.022 and z-score of 2.8, confirming the significance of the positive events.

441

442 Amplified DNA fragments were sequenced to further confirm successful donor DNA insertion at 443 Cas9 target sites. Sequence analysis revealed that the entire length of donor DNA was integrated 444 in the Chlamydomonas chloroplast DNA (Figure 2D). The genomic sequence corresponded to 445 the expected sequence from insertion of the donor DNA at the two Cas9 cleavage sites. Precise 446 donor DNA insertion was observed in Chlamydomonas chloroplasts by the use of an Edit 447 Plasmid that encoded a Cas9 expression cassette, a multiple guide RNA expression cassette and 448 a donor DNA template. 
450

451

452

453

454

455

456

457

458

459

460

461

462

463

464

465

466

467

468

469

470

471

472

473

474

475

476

477

478

479

\section{Analysis for on-target mutations at one Cas9/gRNA target site in Chlamydomonas} chloroplasts

A number of reports showed that Cas9/gRNA induced cleavages in the nucleus are often repaired through non-homologous end joining (NHEJ) pathways, resulting in nucleotide substitutions (SNPs), small insertions and small deletions (INDELs) (Li et al., 2015; Shin et al., 2016). In order to survey whether such mutations occur through Cas9/gRNA in chloroplasts, we constructed several Edit Plasmids that carried sgRNA2c in the guide RNA expression cassette besides Cas9 (YP11, YP31, and YP33; see Table 1). We utilized sgRNA2c as its target site (5'CTTCACCTGTAAATGGACCACGG3', Cas9 cleavage site in bold with PAM sequence in the last three nucleotides) harbored the AvaII restriction sequence ( $A v a \mathrm{II}$ restriction site is GGWCC where $\mathrm{W}$ is either A or T) (Figure 3). Thus, any change such as base substitution and INDELs at the Cas9 cleavage site would result in the loss of $A v a$ II restriction. We used the loss of $A v a$ II restriction to enrich for rare gene edited sequences. This approach of enriching for mutations to a restriction site was used successfully to recover rare Cas9-mediated NHEJ events in nuclear DNA in several previous reports (Jiang et al., 2014; Xie \& Yang, 2013; Xie et al., 2015). The control constructs were YP5 and YP29 without the guideRNA or Cas9, respectively. The cells transformed with these constructs were subjected to DNA extraction and subsequent PCR amplification of the genomic region of the target site using primers $\mathrm{C} 1$ and $\mathrm{C} 4$, and the high fidelity Q5 DNA polymerase (see Figure 2A \& MATERIALS AND METHODS). The amplified DNA samples were digested with AvaII and separated through gel electrophoresis.

There was no clearly visible DNA band on the agarose gel that corresponded to the undigested DNA specific to positive samples, indicating that mutations at the cleavage site occurred infrequently (see supplemental information). To detect rare events of such mutations, we attempted to isolate DNA from the region (700 - $900 \mathrm{bp}$ ) including undigested DNA (795 bp), while wild-type DNA fragments produced by AvaII digestion were 329 and 469 bp long. Extracted DNA fractions were subjected to the cloning into an E.coli vector. Transformed E. coli colonies were sampled randomly and their DNA samples were further analyzed by AvaII digestion and/or direct sequencing (see Figure $3 \&$ Table 4 ). The analysis of 66 clones in total from all Edit Plasmids carrying active Cas9 under strong psaA promoter (YP11 and YP31) showed that four independent clones (6.06\%) had SNPs resulting in the loss of the AvaII site. 
480 The analysis of 100 clones lacking Cas9 (YP5) or guide RNAs (YP29), representing negative

481 controls, showed that seven independent clones (7\%) had SNPs resulting in the loss of the AvaII

482 site. No INDEL mutations were detected in this experiment.

483

\section{Construction of Edit Plasmids for yeast mitochondria}

485 It has previously been shown that plasmids derived from pBR322 were capable of replicating in

486

487

488

489

490

491

492

493

494

495

496

497

498

499

500

501

502

503

504

505

506

507

508

509

510 yeast mitochondria (Fox, Sanford \& McMullin, 1988). To create Edit Plasmid constructs for yeast mitochondria, we used pBR322 as the backbone for the study of Cas9/gRNA-driven genome editing in mitochondria. As shown in Figure 4, the Edit Plasmid constructs contained the following elements similar to the Edit Plasmids for Chlamydomonas chloroplasts: Cas9 expression cassette, guide RNA expression cassette and donor DNA for DNA insertion at Cas9 target sites. In addition, the $C O X 3$ fragment $(0.75 \mathrm{~kb} P a c \mathrm{I}-\mathrm{MboI})$ was used as a screenable marker for mitochondrial transformation with its capability to rescue the $C O X 3$ deletion mutant cox3-10 as described in Fox et al., 1988. The Cas9 expression cassette had the Cas9 coding sequence that was optimized for the expression in yeast mitochondria (Figure S2). As part of codon optimization, the codons that were not used at all or were rarely used in yeast mitochondria were replaced with codons that were used frequently. Also, a number of tryptophan codons were replaced with UGA, which is a stop codon in the universal codon system but is translated into tryptophan in yeast mitochondria (Fox, 1979). This was designed to prevent expression of Cas9 in the cytoplasm after microprojectile DNA transformation. The minimal promoter and terminator of $C O X 2$ gene were used to drive expression of the Cas9 gene. The minimal lengths of 75 and $119 \mathrm{bp}$ of these elements were chosen with the purpose of suppressing spontaneous homologous recombination at the sites and avoiding integration into the mitochondrial genome as shown in Mireau, Arnal \& Fox (2003).

For the guide RNA target sites in yeast mitochondria, we chose the $C O X 1$ gene, encoding subunit I of cytochrome $\mathrm{C}$ oxidase required for oxidative phosphorylation, i.e. respiration. Two sites unique to the mitochondrial genome were selected:

5'TTCTTTGAAGTATCAGGAGGTGG3' (sgRNA1m) and 5'ATGATTATTGCAATTCCAACAGG3' (sgRNA2m) with the last 3 nucleotides as PAM sequences. The sgRNA1m site was localized in exon 4 of the COX1 gene, and the sgRNA2m in exon 5. The two sites are separated by 1258 bp encompassing an intron (Figure 5). Each of 
511 these guide RNA sequence without PAM sequence was fused with the tracrRNA sequence (see

512 METHODS \& MATERIALS). For the guide RNA expression, the gRNA cassette was

513 constructed in 5' to 3' orientation as follows: a minimal COX3 promoter; $t R N A^{P h e}(G A A)$;

514 sgRNA2m; $t R N A^{\operatorname{Tr}}(U C A)$; sgRNA1m; $t R N A^{M e t}(C A U)$ and a minimal $C O X 3$ terminator element

515 (Figure 4). For the donor DNA insertion experiment, the donor DNA contained the GFPm gene 516 that was codon-optimized for the expression in yeast mitochondria (Cohen and Fox, 2001). In

517 addition, one tryptophan codon was changed to UGA, further assuring GFPm expression only in

518 mitochondria. The GFPm coding region in the donor DNA was designed to be in-frame with the 519 COX1 ORF after the donor DNA insertion. Further, the both ends of the donor DNA were fused 520 with the $C O X 1$ genomic sequences at the external junction of the Cas9 cleavage sites. HR1 and

521 HR2 corresponded to two short genomic regions which were each immediately adjacent to the 522 corresponding guide RNA target site (see Figure 4). The length of the homologous region at 523 each end was chosen to be relatively short to minimize spontaneous homologous recombination 524 without Cas9 activity, i.e. 144 bp adjacent to the sgRNA1m site (HR1m), 115 bp adjacent to the 525 sgRNA2m site (HR2m), similar to those shown in Mireau, Arnal \& Fox (2003). Furthermore, 526 sequence variations were included at the guide RNA recognition sites within the donor DNA, so 527 that the replaced mitochondrial DNA would no longer be recognized by the guide RNA/Cas9 528 system. 7 of the 20 nucleotides in the sgRNA1m recognition site have been changed, so as 529 sgRNA2 $\mathrm{m}$ site by deleting 16 nucleotides at the 5' end of the recognition site (see MATERIALS $530 \&$ METHODS). This design was to prevent the deletion of replaced DNA from further genome 531 editing activity and increase the stability of replaced DNA in the presence of the Edit Plasmids. 532

533 Cas9/gRNA-driven donor DNA insertions at Cas9 target sites in yeast mitochondria

534 To assay for donor DNA insertion events through Cas9-induced cleavages, the construct HS8 535 and its control construct HS6 lacking Cas9 were each transformed into a strain lacking 536 mitochondrial DNA $\left(r h o^{\circ}\right)$ as described in MATERIALS \& METHODS. HS8 and HS6, both 537 carried the guide RNA expression cassette and donor DNA with GFPm. The only difference was 538 the presence and absence of the Cas9 expression cassette, respectively. Transformants with each 539 of mitochondrial constructs were identified by subsequent screening for their capability to rescue 540 the cox3 deletion mutant (see MATERIALS \& METHODS). The isolated mitochondrial 541 transformants were then crossed with the strain CUY563, carrying the wild-type mitochondrial 
542 genome, to observe the effect of Edit Plasmids on the mitochondrial genome. Five transformant

543 lines of each construct were subjected to the cross with the wild-type strain on a glucose

544 medium. After 48 hours of incubation, cells were collected and assayed for the donor DNA

545 insertion events by PCR amplification (see MATERIALS \& METHODS). Primer sets were

546 used wherein one primer was from the mitochondrial $C O X 1$ genomic region in the vicinity of the

547 cleavage sites and the other primer was from the donor DNA region (see Figure 5A). This design

548 of primers was to ensure that the desired PCR product could only be amplified from a correctly

549 replaced DNA in the mitochondrial genome but not from the wild-type mitochondrial DNA nor

550 from the Edit Plasmid itself. As shown in Figure 5B, the expected size of the DNA amplicons

551 from each end of the replaced DNA was observed in the HS8 derived cell culture. No DNA

552 fragments were amplified from the culture transformed with the control construct HS6. To

553 further assess the reproducibility of the data, we repeated the same experiment fifteen times

554 starting from the cross between Edit Plasmid lines and wild-type yeast strain, CUY563. The

555 donor DNA insertion was detected from all 15 HS8 samples containing Cas9 but none from 15

556 HS6 samples lacking Cas9. Then, the amplified DNA fragments from three independent crosses

557 between HS8 and CUY563 strains were sequenced directly. Sequence analysis revealed that all

558 amplicon sequences covering the replaced region completely matched that of the donor DNA

559 present in HS8 construct (Figure 5C, supplemental information). These results showed that

560 complete donor DNA insertion was successfully induced by the use of an Edit Plasmid in yeast

561 mitochondria that encodes Cas9 and guide RNA expression cassettes and a donor DNA template.

562

563 Rescue of the Edit Plasmid out of yeast mitochondria and its stability

564 To confirm the presence of HS8 plasmid after the cross with the wild-type mitochondria, we 565 isolated the intact plasmid out of crossed yeast cells. For the plasmid rescue experiment, we 566 sampled cells from the second overnight culture where cells have gone through at least 20

567 generations after the cross. Since the Edit Plasmid line was co-transformed with the nuclear

568 plasmid, pYES2, we digested the total DNA isolated from the cultured cells with ApaI and SphI

569 to eliminate pYES2 from the rescue. Transforming $200 \mathrm{ng}$ of total DNA isolated from the yeast

570 cells into E. coli, we obtained 12 colonies. All of them showed restriction patterns

571 indistinguishable from that of the transforming HS8 construct by two sets of digestions (Figure 
572 6A \& B). This showed that the Edit Plasmid was able to persist even in the presence of the wild573 type mitochondrial DNA.

574

575

576

To address the question of Edit Plasmid stability, we advanced the second culture of crossed cells to two additional overnight cultures. The presence of the HS8 edit plasmid in the series of

577 cultures was analyzed by sampling cells with primer set G-12 to amplify part of the Edit

578 Plasmid, i.e. the donor DNA. As shown in Figure 6C, the donor DNA was detected in the first 579 two cultures in a diminishing manner and it was not detectable in the last two cultures. This 580 demonstrates that the Edit Plasmid tends to cease its presence in mitochondria in the presence of 581 wild-type mitochondrial DNA within about 30-40 generations.

582

\section{DISCUSSION}

584 A plasmid approach enabling organelle genome editing

585 The CRISPR/Cas9 system is a powerful tool to precisely edit genomes of a wide range of 586 prokaryotic and eukaryotic species. However, gene editing in eukaryotes, including yeast 587 Saccharomyces cerevisiae and algal Chlamydomonas reinhardtii, has been restricted to nuclear 588 genomes. There is no published report except one that describes the use of the system on organelle genomes. The sole publication reports that the Cas9 protein expressed in cytoplasm is

590

591

592

593

594

595

596

597

598

599

600

601

602 also localized in human mitochondria, and the simultaneous expression of Cas9 and guide RNA in the cytoplasm resulted in the reduction of the target gene in mitochondria (Jo et al., 2015). While this is an encouraging report, there is no analysis on the change on DNA caused by Cas9 at the nucleotide level. Thus, it is difficult to conclude if the reported change in the overall gene dosage was directly caused by Cas9 induced cleavages or not. Further, if it were direct, the approach would be still limited to the creation of gene knockouts but not to the replacement of DNA with donor DNA because DNA could not be freely imported into mitochondria.

Here we show an original approach that is capable of editing and replacing mitochondrial as well as chloroplast DNA in yeast and alga, respectively. Our approach utilizes plasmids that persist in organelles at least long enough to edit organelle genomes. pBR322 plasmid was reported to replicate in yeast mitochondria (Fox, Sanford \& McMullin, 1988) and chloroplasts of Chlamydomonas (Boynton et al., 1988). The plasmids that were equipped with genome editing elements, which we called Edit Plasmids, were transformed into mitochondria of yeast, 
603 Saccharomyces cerevisiae, and chloroplasts of alga, Chlamydomonas reinhardtii, to test the 604 universal functionality of our approach.

605

606

607

Cas9 induced homology-directed repair (HDR) through donor DNA insertion in organelles

608

Organelles contains their genomes in multiple copies. There are about 50 copies of

609

mitochondrial DNA in yeast (review: Williamson, 2001) and about 83 copies in Chlamydomonas

610 chloroplasts (Gallaher et al., 2018). The genomes in high copy numbers are postulated to be

611 required for keeping the genetic content uniform through active homologous recombination among them. Indeed, active homologous recombination was utilized for transgenic approaches

612 to integrate transgenic DNA into the organelle genomes. For our approach, Edit Plasmids were

613 designed not to integrate into genomes. This autonomous feature is highly desirable for

614 producing the edited cells and organisms without carrying any transgenic elements left in their

615 genomes after the Edit Plasmids are segregated away. For this purpose, we designed expression

616 elements within Edit Plasmids as short as possible to reduce the chance of integration. For

617 instance, promoter and terminator elements to drive Cas9 expression in yeast mitochondria had

618 the length of $74 \mathrm{bp}$ and $119 \mathrm{bp}$, respectively. The same elements for guide RNA expression in

619 yeast mitochondria had $75 \mathrm{bp}$ and $118 \mathrm{bp}$, respectively. For reference, conventional integration

620 experiments in organelles were usually induced by longer DNA homology to the target site such

621 as fragments with the length of $1.6 \mathrm{~kb}$ and $2.3 \mathrm{~kb}$ (Cohen \& Fox, 2001).

622 The other precautious measure that we included in the Edit Plasmids in this study is to

623 differentiate the homologous recombination facilitated by Cas9-induced cleavage from

624 spontaneous recombination without Cas9. For this purpose, we also reduced the length of the

625 homologous regions flanking the donor DNA to about $100 \mathrm{bp}$ or less. As noted above, donor

626 DNA insertion was detected in yeast mitochondria from all 15 HS8 samples containing Cas9 but

627 none from 15 HS6 samples lacking Cas9. Since the control constructs without Cas9 produced no

628 detectable replacement of donor DNA in the organelle genomes, our designs were shown

629 sufficient to accomplish the task. If homologous recombination would have occurred by a single

630 crossover event in the absence of DNA cleavage, the entire Edit Plasmid would have integrated

631 at one of the two homologous regions. Such a product would have been detectable in one of the

632 PCR amplicons of our experiments. Since no such products were detected, we conclude that our 
633 experimental setting was successful in preventing spontaneous homologous recombination by 634 either single or double crossover events.

635 As for the DNA repair system of double-strand breaks in organelles, a number of studies 636 showed that homology-directed repairs (HDR) occur often to preserve genetic information 637 without causing any mutations (review: Stein \& Sia, 2017). Therefore, we presumed that DNA 638 double strand breaks induced by Cas9 will be predominantly repaired by homologous 639 recombination with uncut wild-type DNA. Since the repaired DNA should be identical to the 640 wild-type DNA, the analysis of such events would not be easily measurable. To make the Cas9 641 activity measurable, we focused on experiments to detect donor DNA insertion events at the 642 region that were deleted by two cleavage sites induced by Cas9. The donor DNA fragments 643 were so designed that the guide RNA target sites were eliminated after the homologous 644 recombination to stabilize the replacement events.

645 As summarized in Table 3, the results in Chlamydomonas chloroplasts revealed that only the 646 construct with Cas9 under the strong promoter $p s a A$ and sgRNA1c/2c (YP13) showed

647 Cas9/sgRNA activity, i.e. donor DNA integration by HDR-mediated gene replacement, while the 648 rest, including two controls (YP23 and YP24), did not. Both, the strength of promoters driving 649 Cas9 and the efficacy of the sgRNAs, influence Cas9/sgRNA activity. In chloroplasts, Cas9 650 under a strong promoter ( $p s a A)$ but not under a weak promoter $(p s b D)$ and sgRNA pair $1 \mathrm{c} / 2 \mathrm{c}$ but 651 not sgRNA3c/4c showed Cas9/sgRNA activity. If Cas9-independent homologous recombination 652 would have occurred spontaneously in the two observed events with the strong $p s a A$ promoter, 653 we would have expected to see single-crossover events at one of the homologous regions as the 654 predominant products. This would have resulted in the integration of the entire Edit Plasmid at 655 the recombination site and the PCR amplification of only one of the two ends of the donor DNA 656 integration. Since both ends of the donor DNA were confirmed in the two events by PCR 657 analysis, we conclude that they were the products of double-crossover events at two cleavage 658 sites produced by Cas9. The absence of Cas9-independent recombination events in our 659 experiment is also supported by the fact that we did not observe any integration of either end of 660 the donor DNA among 69 transformants of other constructs, e.g., constructs carrying Cas9 661 driven by a weak promoter. The sequencing of the integration events further confirmed that 662 Cas9-dependent homologous recombination is the primary mode of the precise donor DNA 663 integration. 
664

665

666

667

668

669

670

671

672

673

674

675

676

677

678

679

680

681

682

683

684

685

686

687

688

689

690

691

692

693

With regard to the length of homologous DNA to induce recombination, Dauville et al. (2004) reported no DNA insertion in Chlamydomonas chloroplast above background with the homology shorter than up to $100 \mathrm{bp}$, irrespective of the length of homology at the other end. Examining $2 \times 10^{7}$ cells, they reported that the shortest homology regions capable of recombination were 75 $\mathrm{bp}$ at one end and $121 \mathrm{bp}$ at the other end. Although we did not calculate number of cells in our experiments, we estimate it to be significantly less than $10^{5}$. Thus, we detected targeted donor DNA insertions at a much higher frequency and with much shorter length of homology at the both ends (74 bp and $75 \mathrm{bp}$ ) than the experiments previously reported to be insufficient for recombination insertion in Chlamydomonas chloroplasts (Dauville et al., 2004). In comparison, we detected no donor DNA insertion in 69 transplastomic control lines lacking functional Cas9 or sgRNA. Similarly, donor DNA insertion in yeast mitochondria was confirmed by PCR analysis and DNA sequencing. In this case, the donor DNA was flanked by the short length of homologous regions at the both ends (115 bp and $144 \mathrm{bp}$ ) to suppress spontaneous recombination. As the result, no insertion of the donor DNA was detected in the absence of Cas 9 activity while the insertion was detected in the presence of Cas9 activity in mitochondria.

Although we confirmed the presence of intact GFP gene in both mitochondria and chloroplasts, we were unable to detect GFP fluorescence in either. In yeast, the failure of the detection could be due to the fusion of GFP with the 224 amino acid long, amino-terminal fragment of COX1 protein that is known to contain five transmembrane domains (https://www.uniprot.org/uniprot/A0A0H3WI17). The presumed integration into the inner membrane of mitochondria might have prevented GFP protein to fold properly and active. In the case of Chlamydomonas, the direct detection of GFP signals in cells was known to be challenging (Franklin et al., 2002). Besides, the target site we selected in the psaA gene was known to be trans-spliced with remaining parts of mRNA to produce the full-length mRNA for protein synthesis in chloroplasts (Choquet et al., 1988). It remains to be answered whether or not the insertion of GFP donor DNA affected the proper trans-splicing the RNA transcribed from the recombined region. 
694 Despite the lack of GFP signals, these experimental designs resulted in the demonstration of

695 functional Cas9 activity introduced by the Edit Plasmids in two distinct organelles in two distinct

696 organisms. Integration of donor DNA at the Cas9 target sites was complete without leaving any

697 nucleotide alteration. To our knowledge, this is the first demonstration of Cas 9 induced donor

698 DNA insertions mediated by Cas9/guideRNAs in mitochondria and chloroplasts. Organelle

699 genomes have constitutions and environments distinct from the nucleus. For example, some

700 mitochondrial genomes are low in GC content, (17\% in yeast mitochondria; Foury et al., 1998)

701 and $\mathrm{pH}$ milieu is different from the other part of cells ( $\mathrm{pH} 7.5$ in yeast mitochondria whereas

702 pH7.2 in the cytoplasm; Orij et al., 2009). Our results further demonstrate that the CRISPR/Cas9

703 system is functional in both nuclear and organelle genomes. We found no evidence of Cas9

704 toxicity in stably transformed yeast and algal organelles unlike that previously reported for

705 nuclear expression of Cas9 expression in Chlamydomonas (Jiang et al., 2018).

706

707

708

No evidence of Cas9 induced INDEL mutations at a Cas9 target site in Chlamydomonas

chloroplasts

709 Double-stranded DNA breaks induced by Cas9/sgRNA can be repaired either by homology-

710 directed repair (HDR) or by non-homologous end joining (NHEJ) pathways in the nucleus. The

711 latter often results in mutations, including small insertions, deletions, or substitutions at or close

712 to cleavage sites (Brinkman et al., 2018). We showed the former repair system is active in

713 organelles as discussed above. We further explored possible repairs of dsDNA breaks by NHEJ

714 by analyzing one of the Cas 9 target sites that harbored a site recognized by a DNA restriction

715 enzyme. We made use of the site to screen any change created by NHEJ repairs. Enriching such

716 changes by $A v a$ II enzyme digestion, gel separation, cloning the $A v a$ II-resistant amplicon, and

717 sequencing the cloned amplicon, we detected 4 events of nucleotide substitutions out of 90

718 (4.44\%) clones with enriched amplicons from the cells transformed with Cas9/gRNA active

719 constructs (YP11, YP31 and YP33) (Table 4). Considering the psbD promoter is insufficient for

720 Cas9 activity as we showed above, the frequency of substitutions in relevant constructs (YP11

721 and YP31) is 4/66 =6.06\% whereas the control constructs (YP5 and YP29) had seven nucleotide

722 substitutions out of 100 enriched clones. The results indicate that the SNPs detected at the AvaII

723 site in experimental lines and control lines are statistically similar and not a consequence of

724 Cas9- induced SNPs. Enrichment of mutations at the AvaII recognition site is not due to Cas9 
725 activity since they are found in similar frequency in the control lines without Cas9 or sgRNA.

726 They likely represent enrichment of preexisting native polymorphisms or PCR errors at the AvaII

727 site by our strategy for enriching the AvaII resistant clones. Based on our data, we did not find

728 evidence for NHEJ DNA repair in chloroplasts. This is consistent with prior reports in

729 Chlamydomonas chloroplasts and in mitochondria of higher plants, showing the lack of NHEJ

730 repair events (Odom et al., 2008; and Kazama et al., 2019, respectively). In the latter, the

731 engineered TALEN targeted to mitochondria was used to create a specific DNA cleavage.

732 Through thorough molecular analyses, they demonstrated that the cleavage was not repaired by

733 non-homologous end joining (NHEJ) mechanisms but by homology-dependent recombination.

734 Similar findings were reported by others, discussing the absence of the conserved KU proteins

735 involved in NHEJ repair in Chlamydomonas chloroplasts (Kwon et al., 2010). As most bacteria

736 have low or no NHEJ repair systems (Gomaa et al., 2014; Citorik et al., 2014; Su et al., 2016),

737 the lack of NHEJ in organelles may reflect their prokaryotic ancestry in evolution. In Cas9

738 based genome editing in nuclear genomes, INDELs are the most common mutations observed at

739 cleavage sites and are advantageous for knocking out genes encoded in the nucleus (Li et al.,

740 2015; Shin et al., 2016). Our results reveal that such knockout mutations are difficult to obtain in

741 organelles. When such mutagenesis is required in organelles, an optimal approach is to introduce

742 specific substitutions through donor DNA insertion at the site induced by two cleavages as we

743 showed in this report.

744

\section{Edit Plasmids maintain their autonomy in organelles}

746 The autonomous nature of the Edit Plasmids is beneficial for their application in organelle

747 genome editing. It ensures an easy removal of transgenic components of Cas9 and guide RNAs

748 after editing is completed. It also allows the complete removal of Cas9 activity by a simple

749 segregation. We provide evidence that the Edit plasmids persist long enough to induce gene

750 editing. To demonstrate the persistence of the Edit Plasmid, we performed the isolation of the

751 Edit Plasmid out of yeast cells. The cells were grown over 20 generations after crossing the Edit

752 plasmid and the wild-type mitochondrial genome together. We could successfully retrieve intact

753 Edit Plasmid. Without any positive selection, Edit Plasmids tend to segregate away after many

754 generations as shown for yeast mitochondria in this study. To prolong the activity of Edit

755 Plasmids and to obtain the homoplasmic state of engineered DNA, we plan to test mitochondrial 
756 rep/ori elements that are more efficient than the one carried on pBR322 or have a selectable

757 marker on the Edit Plasmid, such as ARG8m for yeast (Bonnefoy \& Fox, 2000), to enhance their

758 stability. Our goal is to extend this technology to crop plants without the use of a selectable

759 marker for regulatory considerations and public acceptance.

760

761

\section{CONCLUSIONS}

763 Organelle genome editing has been underexplored in comparison with that of nuclear genes. We

764

765

766

767

768

769

770

771

772

773

774

775

776

\section{ACKNOWLEDGEMENT}

778

779

780

781

782

783

784

785 healthcare. for her assistance in laboratory work.

\section{REFERENCES} AMB Express 4:57.

report the first demonstration of Cas9 based genome editing in organelles. Our novel approach utilizing Edit Plasmids was successful in inducing donor DNA insertion at the target sites cleaved by Cas9/gRNAs in yeast mitochondria as well as in algal chloroplasts. The frequency of substitutions and INDEL mutations at a cleavage site was below detection in our study, indicating that homology-directed DNA repair \& replacement are the main outcomes of Cas9 induced cleavages in organelles. The approach with Edit Plasmids is expected to open the door to edit organelle DNA precisely as well as to introduce new alleles and genes without leaving any trace of transgenes. Future experiments will address the following: increasing the efficiency of organelle genome editing via CRISPR/Cas9; and the use of CRISPR/Cas9 to digest unmodified organelle DNA and promote homoplasmy. Possible application areas of the organelle genome editing are wide, impacting agriculture, industrial biotechnology and human

We thank Dr. Thomas Fox for providing yeast strains and other materials, and Victoria Kuhnel

Almaraz-Delgado AL, Flores-Uribe J, Pérez-España VH, Salgado-Manjarrez E., Badillo-Corona JA. 2014. Production of therapeutic proteins in the chloroplast of Chlamydomonas reinhardtii. 
786 Avalos JL, Fink GR, Stephanopoulos G. 2013. Compartmentalization of metabolic pathways in

787 yeast mitochondria improves the production of branched-chain alcohols. Nature Biotechnology $788 \quad 31: 335-341$.

789

790 Barrera D, Gimpel J, Mayfield S. 2014. Rapid screening for the robust expression of 791 recombinant proteins in algal plastids. Methods in Mololecular Biology 1132:391-399. DOI:

792 10.1007/978-1-62703-995-6_26.

793

794 Bertalan I, Munder MC, Weiß C, Kopf J, Fischer D, Johanningmeier U. 2015. A rapid, modular 795 and marker-free chloroplast expression system for the green alga Chlamydomonas reinhardtii. 796 Journal of Biotechnology 195:60-66. DOI: 10.1016/j.jbiotec.2014.12.017.

797

798 Bonnefoy N, Fox TD. 2000. In vivo analysis of mutated initiation codons in the mitochondrial 799 COX2 gene of Saccharomyces cerevisiae fused to the reporter gene ARG8m reveals lack of 800 downstream reinitiation. Mol Gen Genet 262:1036-1046.

801

802 Bonnefoy N, Fox TD. 2007. Directed Alteration of Saccharomyces cerevisiae mitochondrial 803 DNA by biolistic transformation and homologous recombination. Methods in Molecular Biology 804 372: 153-166.

805

806 Boynton JE, Gillham NW, Harris EH, Hosler JP, Johnson AM, Jones AR, Randolph-Anderson 807 BL, Robertson D, Klein TM, Shark KB, Sanford JC. 1988. Chloroplast transformation in 808 Chlamydomonas with high velocity microprojectiles. Science 240:1534-1538.

809

810 Brinkman EK, Chen T, de Haas M, Holland HA, Akhtar W, van Steensel B. 2018. Kinetics and 811 fidelity of the repair of Cas-9-induced double-strand DNA breaks. Molecular Cell 70:801-813. 812 DOI: 10.1016/j.molcel.2018.04.016.

813

814 Choquet Y, Goldschmidt-Clermont M, Girard-Bascou J, Kück U, Bennoun P, Rochaix J-D.

815 1988. Mutant phenotypes support a trans-splicing mechanism for the expression of the tripartite 816 psaA gene in the C. reinhardtii chloroplast. Cell 52: 903-913. 
817

818 Citorik RJ, Mimee M, Lu TK. 2014. Sequence-specific antimicrobials using efficiently delivered 819 RNA-guided nucleases. Nature Biotechnology 32: 1141-1145. DOI:10.1038/nbt.3011.

820

821 Cohen JS, Fox TD. 2001. Expression of green fluorescent protein from a recoded gene inserted 822 into Saccharomyces cerevisiae mitochondrial DNA. Mitochondrion 1:181-189.

823

824 Conde, J, Fink, GR. 1976. A mutant of Saccharomyces cerevisiae defective for nuclear fusion. 825 Proceedings of the National Academy of Sciences of the United States of America 73: 36518263655.

827

828 Cong L, Ran FA, Cox D, Lin S, Barretto R, Habib N, Hsu PD, Wu X, Jiang W, Marraffini LA, 829 Zhang F. 2013. Multiplex genome engineering using CRISPR/Cas systems. Science 339:819830823.

831

832 Costanzo MC, Fox TD. 1993. Suppression of a defect in the 5' untranslated leader of 833 mitochondrial $C O X 3$ mRNA by a mutation affecting an mRNA-specific translational activator 834 protein. Molecular and Cellular Biology 13: 4806-4813.

835

836 Cummins PL, Kannappan B, Gready JE. 2018. Directions for optimization of photosynthetic 837 carbon fixation: RuBisCO's efficiency may not be so constrained after all. Frontier in Plant 838 Science 9:183. DOI: 10.3389/fpls.2018.00183.

839

840 Dauvillee D, Hilbig L, Preiss S, Johanningmeier U. 2004. Minimal Extent of Sequence

841 Homology Required for Homologous Recombination at the psbA Locus in Chlamydomonas

842 reinhardtii Chloroplasts using PCR-generated DNA Fragments. Photosynthesis Research 843 79:219-224.

844

845 Estavillo GM, Crisp PA, Pornsiriwong W, Wirtz M, Collinge D, Carrie C, Giraud E, Whelan J, 846 David P, Javot H, Brearley C, Hell R, Marin E, Pogson BJ. 2011. Evidence for a SAL-PAP 
847 chloroplast retrograde pathway that functions in drought and high light signaling in Arabidopsis.

848 Plant Cell 23:3992-4012.

849

850 Foury F., Roganti T, Lecrenier N, Purnelle B. 1998. The complete sequence of the mitochondrial 851 genome of Saccharomyces cerevisiae. FEBS Letters 440:325-331.

852

853 Fox TD. 1979. Five TGA "stop" codons occur within the translated sequence of the yeast

854 mitochondrial gene for cytochrome c oxidase subunit II. Proceedings of the National Academy of 855 Sciences of the United States of America 76:6534-6538.

856

857 Fox TD, Sanford JC, McMullin TW. 1988. Plasmids can stably transform yeast mitochondria 858 lacking endogenous mtDNA. Proceedings of the National Academy of Sciences of the United 859 States of America 85:7288-7292.

860

861 Franklin S, Ngo B, Efuet E, Mayfield SP. 2002. Development of a GFP reporter gene for 862 Chlamydomonas reinhardtii chloroplast. The Plant Journal 30:733-744.

863

864 Gallaher SD, Fitz-Gibbon ST, Strenkert D, Purvine SO, Pellegrini M, Merchant SS. 2018. High865 throughput sequencing of the chloroplast and mitochondrion of Chlamydomonas reinhardtii to

866 generate improved de novo assemblies, analyze expression patterns and transcript speciation, and 867 evaluate diversity among laboratory strains and wild isolates. Plant Journal 93:545-565. DOI: $86810.1111 /$ tpj.13788.

869

870 Gomaa AA, Klumpe HE, Luo ML, Selle K, Barrangou R, Beisel CL. 2014. Programmable 871 removal of bacterial strains by use of genome-targeting CRISPR-Cas systems. mBio 5:e00928872 13. DOI:10.1128/mBio.00928-13.

873

874 Green-Willms NS, Butler CA, Dunstan HM, Fox TD. 2001. Pet111p, an inner membrane-bound 875 translational activator that limits expression of the Saccharomyces cerevisiae mitochondrial gene 876 COX2. Journal of Biological Chemistry 276:6392-6397.

877 
878 Haeussler M, Schönig K, Eckert H, Eschstruth A, Mianné J, Renaud JB, Schneider-Maunoury S, 879 Shkumatava A, Teboul L, Kent J, Joly JS, Concordet JP. 2016. Evaluation of off-target and on880 target scoring algorithms and integration into the guide RNA selection tool CRISPOR. Genome 881 Biology 17:148-159 DOI 10.1186/s13059-016-1012-2.

882

883 Hanson MR, Bentolila S. 2004. Interactions of mitochondrial and nuclear genes that affect male 884 gametophyte development. Plant Cell 16:S154-S169.

885

886

Ishiga Y, Watanabe M, Ishiga T, Tohge T, Matsuura T, Ikeda Y, Hoefgen R, Fernie AR, Mysore 887 KS. 2017. The SAL-PAP chloroplast retrograde pathway contributes to plant immunity by 888 regulating glucosinolate pathway and phytohormone signaling. MPMI 30:829-841. DOI:

889 10.1094/MPMI-03-17-0055-R.

890

891

Jaganathan D, Ramasamy K, Sellamuthu G, Jayabalan S, Venkataraman G. 2018. CRISPR for 892 Crop Improvement: An update review. Frontier in Plant Science DOI: 10.3389/fpls.2018.00985.

893

894 Jiang W, Brueggeman AJ, Horken KM, Plucinak TM, Week DP. 2014. Successful Transient 895 Expression of Cas9 and Single Guide RNA Genes in Chlamydomonas reinhardtii. Eukaryotic 896 Cell 13:1465-1469.

897

898 Jin S, Daniell, H. 2015. Engineering chloroplast genome just got smarter. Trends in Plant 899 Science 20:622-640. DOI 10.1016/j/tplants.2015.07.004.

900

901 Jo A, Ham S, Lee GH, Lee YI, Kim SS, Lee YS, Shin JH, Lee Y. 2015. Efficient mitochondrial 902 genome editing by CRISPR/Cas9. BioMed Research International 2015, Article ID 305716. 903 http://dx.doi.org/10.1155/2015/305716.

904

905 Kasai S, Yoshimura S, Ishikura K, Takaoka Y, Kobayashi K, Kato K, Shinmyo A. 2003. Effect 906 of coding regions on chloroplast gene expression in Chlamydomonas reinhardtii. Journal of 907 Bioscience and Bioengineering 95:276-282.

908 
909 Kazama T, Okuno M, Watari Y, Yanase S, Koizuka C, Tsuruta Y, Sugaya H, Toyoda A, Itoh T, 910 Tsutsumi N, Toriyama K, Koizuka N, Arimura SI. 2019. Curing cytoplasmic male sterility via 911 TALEN-mediated mitochondrial genome editing. Nature Plants 5:722-730. DOI:

912 10.1038/s41477-019-0459-z.

913

914 Kwon T, Huq E, and Herrin, DL. 2010. Microhomology-mediated and nonhomologous repair of 915 a double-strand break in the chloroplast genome of Arabidopsis. Proceedings of the National 916 Academy of Sciences of the United States of America 107: 3954-13959.

917

918 Leslie M. 2018. 'Old' genome editors might treat mitochondrial diseases. Science 361:1302.

919

920

Li Z, Liu ZB, Xing A., Moon BP, Koellhoffer JP, Huang L, Ward RT, Clifton E, Falco SC, 921 Cigan AM. 2015. Cas9-guide RNA directed genome editing in soybean. Plant Physiology 169: 922 960-970. DOI: 10.1104/pp.15.00783.

923

924

Mireau, H, Arnal, N, Fox, TD. 2003. Expression of Barstar as a selectable marker in yeast 925 mitochondria. Molecular Genetics \& Genomics 270:1-8.

926

927

McBride KE, Svab Z, Schaaf DJ, Hogan PS, Stalker DM, Maliga P. 1995. Amplification of a 928 chimeric Bacillus gene in chloroplasts leads to an extraordinary level of an insecticidal protein in 929 tobacco. Biotechnology 13:362-365.

930

931

McInerney P, Adams P, Hadi MZ. 2014. Error rate comparison during polymerase chain reaction 932 by DNA polymerase. Molecular Biology International 2014: Article ID 287430. DOI:

933 $10.1155 / 2014 / 287430$.

934

935 Michelet L, Lefebvre-Legendre L, Burr SE, Rochaix JD, Goldschmidt-Clermont M. 2011.

936 Enhanced chloroplast transgene expression in a nuclear mutant of Chlamydomonas. Plant

937 Biotechnology Journal 9:565-574. DOI: 10.1111/j.1467-7652.2010.00564.x. 
939 Mireau H, Arnal N, Fox TD. 2003. Expression of Barstar as a selectable marker in yeast

940 mitochondria. Mol Gen Genomics 270:1-8. DOI: 10.1007/s00438-003-0879-2.

941

942 Morley SA, Nielsen BL. 2016. Chloroplast DNA copy number changes during plant

943 development in organelle DNA polymerase mutants. Frontiers in Plant Science 7:57.

944 DOI: $10.3389 /$ fpls.2016.00057.

945

946 Nakamura Y, Gojobori T, Ikemura T. 2000. Codon usage tabulated from international DNA

947 sequence databases: status for the year 2000. Nucleic Acids Research 28: 292

948

949 Nielsen AZ, Mellor SB, Vavitsas K, Wlodarczyk AJ, Gnanasekaran T, de Jesus MPRH, King

950 BC, Bakowski K, Jensen PE. 2016. Extending the biosynthetic repertoires of cyanobacteria and 951 chloroplasts. The Plant Journal 87:87-102.

952

953 Noor-Mohammadi S, Pourmir, A, Johannes TW. 2012. Method to assemble and integrate

954 Biochemical Pathways into the chloroplast genome of Chlamydomonas reinhardtii.

955 Biotechnology \& Bioengineering 109:2896-2903. DOI:10.1002/bit.24569.

956

957 Odom OW, Baek K-H, Dani RN, Herrin DL. 2008. Chlamydomonas chloroplasts can use short

958 dispersed repeats and multiple pathways to repair a double-strand break in the genome. Plant

959 Journal 53:842-853.

960

961 Oey M, Lohse M, Kreikemeyer B, Bock R. 2009. Exhaustion of the chloroplast protein synthesis

962 capacity by massive expression of a highly stable protein antibiotic. The Plant Journal 57:436-45

963 DOI 10.1111/j.1365-313X.2008.03702.x.

964

965 Orij R, Postmus J, Beek AT, Brul S, Smits GJ. 2009. In vivo measurement of cytosolic and 966 mitochondrial $\mathrm{pH}$ using a pH-sensitive FP derivative in Saccharomyces cerevisiae reveals a 967 relation between intracellular $\mathrm{pH}$ and growth. Microbiology 155: 268-278. DOI:

968 10.1099/mic.0.022038-0.

969 
970 Ramesh VM, Bingham SE, Webber AN. 2011. A simple method for chloroplast transformation

971 in Chlamydomonas reinhardtii. Methods in Molecular Biology 684:313-620. DOI: 10.1007/978-

972 1-60761-925-3_23.

973

974 Roberg KJ, Crotwell M, Espenshade P, Gimeno R, Kaiser CA. 1999. LST1 is a SEC24

975 homologue used for selective export of the plasma membrane ATPase from the endoplasmic

976 reticulum. The Journal of Cell Biology 145:659-672.

977

978 Sherman F, Fink GR, Hicks JB. 1986. Methods in Yeast Genetics. Cold Spring Harbor

979 Laboratory, Cold Spring Harbor, N.Y.

980

981 Shin SE, Lim JM, Koh HG, Kim EK, Kang NK, Jeon s, Kwon S, Shin WS, Lee B, Hwangbo K, 982 Kim J, Ye SH, Yun JY, Seo H, Oh HM, Kim KJ, Kim JS, Jeong WJ, Chang YK, Jeong BR.

983 2016. CRISPR/Cas9-induced knockout and knock-in mutations in Chlamydomonas reinhardtii.

984 Scientific Reports 6:27810. DOI:10.1038/srep27810.

985

986 Su T, Liu F, Gu P, Jin H, Chang Y, Wang Q, Liang Q, Qi Q. 2016. CRISPR-Cas9 assisted non 987 homologous end-joining strategy for one-step engineering of bacterial genome. Scientific 988 Reports 6:37895.

989

990 Stein A, Sia EA. 2017. Mitochondrial DNA repair and damage tolerance. Frontiers in 991 Bioscience 22:990-943.

992

993 Svab Z, Hajdukiewicz P and Maliga P. 1990. Stable transformation of plastids in higher plants.

994 Proceedings of the National Academy of Sciences of the United States of America 87: 85269958530.

996

997 Turk EM, Das V, Seibert RD, Andrulis ED. 2013. The mitochondrial RNA landscape of

998 Saccharomyces cerevisiae. PLoS ONE 8:e78105. DOI: 10.1371/journal.pone.0078105. 999 
1000 Viitanen PV, Devine AL, Khan MS, Deuel DL, Van Dyk DE, Daniell H. 2004. Metabolic

1001 engineering of the chloroplast genome using the Echerichia coli ubiC gene reveals that

1002 chorismite is a readily abundant plant precursor for p-hydroxybezoic acid biosynthesis. Plant

1003 Physiology 136:4048-4060.

1004

1005 Williamson D. 2001. The curious history of yeast mitochondrial DNA. Nature Review Genetics

$1006 \quad 3: 1-7$.

1007

1008 Xie K, Minkenberg B, Yang Y. 2015. Boosting CRISPR/Cas9 multiplex editing capability with

1009 the endogenous tRNA-processing system. Proceedings of the National Academy of Sciences 112:

1010 3570-3575. DOI:10.1073/pnas.1420294112.

1011

1012 Xie K, Yang Y. 2013. RNA-Guided Genome Editing in Plants Using a CRISPR-Cas System.

1013 Molecular Plant 6: 1975-1983.

1014

1015 Xing H-L, Dong L, Wang Z-P, Zhang H-Y, Han C-Y, Liu B, Wang X-C, and Chen Q-J. 2014. A

1016 CRISPR/Cas9 toolkit for multiplex genome editing in plants. BMC Plant Biology 14:327

1017

1018 Young RE, Purton S. 2014. Cytosine deaminase as a negative selectable marker for the

1019 microalgal chloroplast: a strategy for the isolation of nuclear mutations that affect chloroplast

1020 gene expression. Plant Journal 80:915-925. DOI: 10.1111/tpj.12675.

1021

1022 
Figure 1

Schematic representation of the Edit Plasmids for Chlamydomonas chloroplasts

See MATERIALS AND METHODS for details.

Scales for Cas9c, and for sgRNA and GFPc were shown in kb.

A.

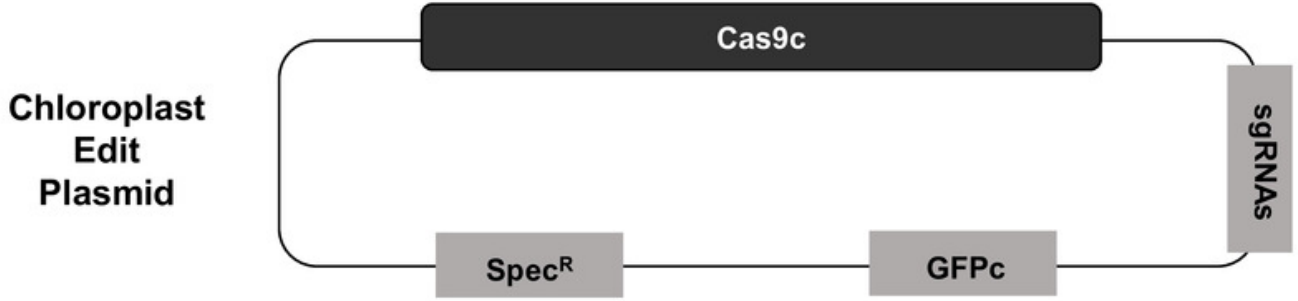

B. Cas 9

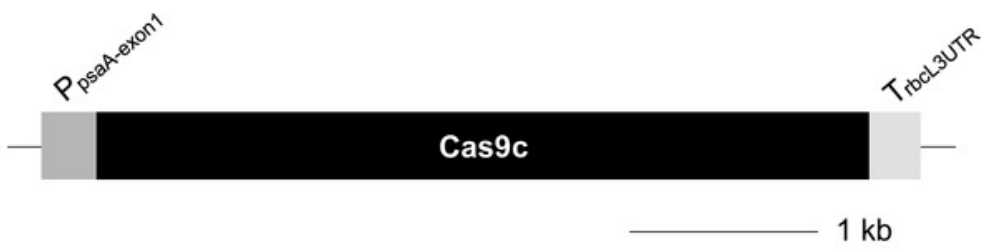

C. SgRNA

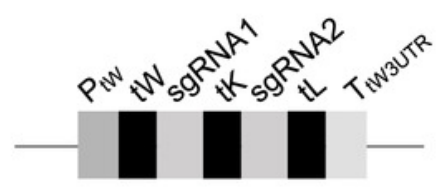

$0.5 \mathrm{~kb}$

D. GFP

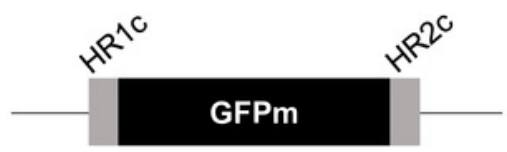




\section{Figure 2}

\section{Replacement of the chloroplast genome with donor DNA by Cas9/gRNA.}

A: Schematic view of the psaA-E3 genomic region targeted by two gRNAs (vertical arrows) and the donor DNA composed of codon-optimized GFPc gene that is provided by the Edit Plasmid. The recognition sites of primers used for the amplification of the junction regions are indicated $(\mathrm{C} 1-\mathrm{C} 4)$.

B: PCR amplification of the junction region of the replaced DNA. Pooled DNAs extracted from independent colonies was used as templates with primers $\mathrm{C} 2 \& \mathrm{C} 4$. Total number of colonies for each Edit Plasmids was 20 for YP13, 17 for YP14, 10 for YP21, 10 for YP22, 16 for YP23 \& 24. Template for Lane 14 was untransformed wild-type cells. C2/C4 amplicon was 852 bp long. M: $1 \mathrm{~kb}$ plus molecular weight marker (New England Biolabs).

C: De-convolution of junction-PCR positive pools of YP13 transformants. Twelve events of the positive pools from Lanes $2 \& 3$ of Panel B were analyzed by two primer sets C2/C4 and C1/C3 to amplify the left and right junction regions, respectively. Events \#2 and \#9 carried replaced DNA. C1/C3 amplicon was 712 bp long. D: The sequence obtained from PCR amplification of the replacement DNA locus in Chlamydomonas plastid DNA modified by the Edit Plasmid approach. Underlined sequences: Wild-type chloroplast genomic sequence that are not present on the Edit Plasmid. Sequences in bold: homologous regions (HR1c and HR2c) present in the donor DNA on the Edit Plasmid. Sequences in bold underlined: Modified gRNA target sites present in the donor DNA. Sequences with double underlines: Silent mutations at the 3' side of guide RNA sites to preclude re-cleavage by Cas9/sgRNA.

D: The sequence obtained from PCR amplification of the replacement DNA locus in Chlamydomonas plastid DNA modified by the Edit Plasmid approach. Underlined sequences: Wild-type chloroplast genomic sequence that are not present on the Edit Plasmid. Sequences in bold: homologous regions (HR1c and HR2c) present in the donor DNA on the Edit Plasmid. Sequences in bold underlined: Modified gRNA target sites present in the donor DNA. Sequences with dotted underlines: Silent mutations at the 3 ' side of guide RNA sites to preclude re-cleavage by Cas9/sgRNA. 
Figure 2.

A.

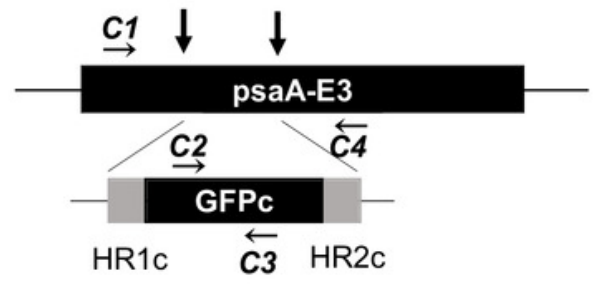

B.

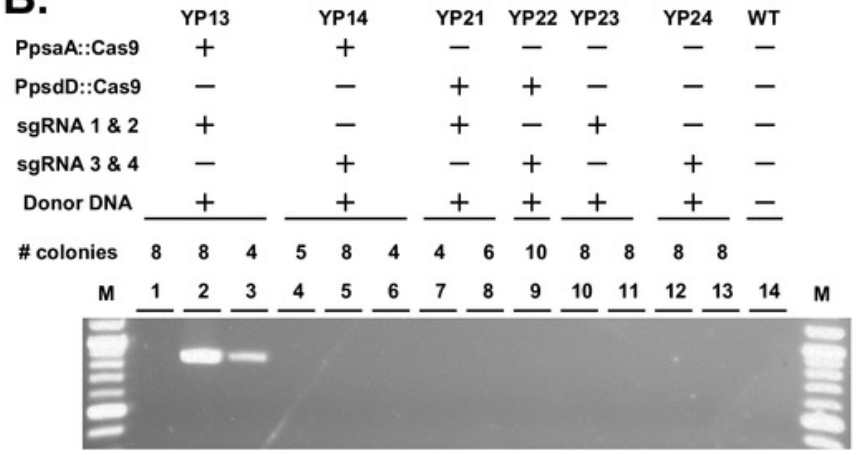

C. $\mathrm{C} 2 \& \mathrm{C} 4$ $\mathrm{C} 1 \& \mathrm{C} 3$

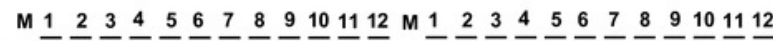
E
D.

GCTGGTTGGTTCCACTACCACAAAGCTGCTCCAAAACTAGAATGGTTC CAAAACGTTGAATCAATGTTAAACCACCACTTAGGTGGTCTTCTTGGT TTAGGTAGTTTAGCTTGGGCTGGTCACCAAATTCACGTTTCTTTACCA GTAAACAAATTATTAGATGCTGGTGTAGATCCAAAAGAAATTCCACTT CCTCATGATTTATTATTAAATCGTGCTATTATGGCTGACTTATACCCA AGTTTTGCTAAAGGTATTGCTCCTTTCTTTACTTTAAACTGGAGTGAA TACAGTGATTTCTTAACATTTAAAGGTGGTTTAAACCCTGTTACATTA TCAGGTTCTGCTGGTTCAGCAGCTGGT ATGGCTAAAGGTGAAGAATTA TTCACAGGTGTTGTACCTATTTTAGTAGAATTAGACGGTGATGTAAAC GGTCACAAATTTTCAGTTTCTGGTGAAGGTGAAGGTGACGCAACTTAT GGTAAATTAACACTTAAATTCATTTGTACTACAGGTAAATTACCAGTA CCTTGGCCATCATTAGTTACAACTTTTACATACGGTGTACAATGTTTC AGTCGTTACCCTGATCACATGAAACAACATGACTTTTTCAAATCTGCT ATGCCAGAAGGTTATGTTCAAGAACGTACTATTTTTTTCAAAGATGAC GGTAATTATAAAACACGTGCTGAAGTAAAATTTGAAGGTGATACTTTA GTTAACCGTATTGAATTAAAAGGTATTGACTTCAAAGAAGATGGTAAT ATTTTAGGTCACAAACTTGAATATAACTACAATTCACATAACGTATAT ATTATGGCAGACAAACAAAAAAATGGTATTAAAGTAAACTTTAAAATT CGTCATAATATCGAGGATGGTTCTGTACAATTAGCTGACCACTATCAA CAAAACACACCAATTGGTGATGGTCCTGTTTTACTTCCAGACAATCAT TATTTAAGTACTCAATCTGCTTTATCAAAAGATCCTAACGAAAAACGT GACCACATGGTATTACTTGAATTTGTTACAGCAGCTGGTATTACTCAC GGTATGGATGAATTATACAAATAATCCATTTACAGGTGAAGGTCACGT TGGTTTATATGAAATTTTAACAACTTCTTGGCATGCACAATTAGCTAT TAACTTAGCTTTATTTGGTTCGTTATCAATTATTGTAGCTCACCACAT GTACGCAATGCCTCCATACCCTTATTTAGCTACTGATTACGGTACACA ATTATCATTATTTACACACCACACATGGATTGGTGGTTTCTGTATTGT TGGTGCTGGTGCTCACGCAGCTATTTTCATGGTTCGTGACTACGATCC TACTAATAACTACAACAACTTATTAGACCGTGTAATTCGTCACCGTGA TGCTATTATTTCTCAC 


\section{Figure 3}

Detection of SNPs at Cas9/sgRNA2c cleavage site in Chlamydomonas chloroplasts

DNA Sequences ( $5^{\prime}$ to $3^{\prime}$ ) near the cleavage site in cloned amplicons lacking the Avall site are aligned with the wild-type parent DNA shown on the top line. Deduced amino acid sequence is shown under each DNA sequence. The 20-nucleotide target sequence for the Cas9/sgRNA complex is indicated in blue. The PAM site (in green), the Avall recognition site (in bold blue), and SNPs and the resulting amino acid changes (in red) are also labelled.

\begin{tabular}{|c|c|c|c|c|c|c|c|c|c|c|c|}
\hline \multirow[b]{2}{*}{ parent } & \multicolumn{5}{|c|}{$\underline{\text { PAM }}$} & \multicolumn{2}{|c|}{ AvaII } & \multirow[b]{2}{*}{$\begin{array}{l}\text { TTT } \\
\text { F }\end{array}$} & \multirow[b]{2}{*}{$\begin{array}{c}\mathrm{ACA} \\
\mathrm{T}\end{array}$} & \multirow[b]{2}{*}{$\begin{array}{c}\text { GGT } \\
\text { G }\end{array}$} & \multirow[b]{2}{*}{$\begin{array}{c}\text { GAA } \\
\mathrm{E}\end{array}$} \\
\hline & $\begin{array}{l}\text { TTA } \\
\text { L }\end{array}$ & $\begin{array}{c}\text { GAA } \\
\text { E }\end{array}$ & $\begin{array}{c}\mathrm{GCT} \\
\mathrm{A}\end{array}$ & $\begin{array}{c}\mathrm{CAC} \\
\mathrm{H}\end{array}$ & $\begin{array}{c}\text { CGT } \\
\text { R }\end{array}$ & $\begin{array}{c}\text { GGT } \\
\mathrm{G}\end{array}$ & $\begin{array}{c}\overline{C C} A \\
P\end{array}$ & & & & \\
\hline 21 & $\begin{array}{l}\text { TTA } \\
\text { L }\end{array}$ & $\begin{array}{c}\text { GAA } \\
E\end{array}$ & $\begin{array}{c}\mathrm{GCT} \\
\mathrm{A}\end{array}$ & $\begin{array}{c}\mathrm{CAC} \\
\mathrm{H}\end{array}$ & $\begin{array}{c}\mathrm{CGT} \\
\mathrm{R}\end{array}$ & $\begin{array}{c}\text { GGC } \\
\text { G }\end{array}$ & $\begin{array}{c}\mathrm{CCA} \\
\mathrm{P}\end{array}$ & $\begin{array}{c}\mathrm{TTT} \\
\mathrm{F}\end{array}$ & $\begin{array}{c}\mathrm{ACA} \\
\mathrm{T}\end{array}$ & $\begin{array}{c}\text { GGT } \\
\text { G }\end{array}$ & $\begin{array}{c}\text { GAA } \\
\mathrm{E}\end{array}$ \\
\hline P11b & $\begin{array}{c}\text { TTA } \\
\text { L }\end{array}$ & $\begin{array}{c}\text { GAA } \\
\mathrm{E}\end{array}$ & $\begin{array}{c}\mathrm{GCT} \\
\mathrm{A}\end{array}$ & $\begin{array}{c}\mathrm{CAC} \\
\mathrm{H}\end{array}$ & $\begin{array}{c}\mathrm{CGT} \\
\mathrm{R}\end{array}$ & $\begin{array}{c}\text { GGT } \\
\text { G }\end{array}$ & $\begin{array}{c}\mathrm{TC} A \\
\mathrm{~S}\end{array}$ & $\begin{array}{c}\text { TTT } \\
\text { F }\end{array}$ & $\begin{array}{c}\mathrm{ACA} \\
\mathrm{T}\end{array}$ & $\begin{array}{c}\text { GGT } \\
\text { G }\end{array}$ & $\begin{array}{c}\text { GAA } \\
\mathrm{E}\end{array}$ \\
\hline P31a & $\begin{array}{c}\text { TTA } \\
\text { L }\end{array}$ & $\begin{array}{c}\text { GAA } \\
\text { E }\end{array}$ & $\begin{array}{c}\text { GCT } \\
\text { A }\end{array}$ & & $\begin{array}{c}\text { CGT } \\
\text { R }\end{array}$ & $\begin{array}{c}\text { GGT } \\
\text { G }\end{array}$ & $\begin{array}{c}\mathrm{TCA} \\
\mathrm{S}\end{array}$ & $\begin{array}{c}\text { TTT } \\
\text { F }\end{array}$ & $\begin{array}{c}\mathrm{ACA} \\
\mathrm{T}\end{array}$ & $\begin{array}{c}\text { GGT } \\
\text { G }\end{array}$ & $\begin{array}{c}\text { GAA } \\
E\end{array}$ \\
\hline P31b & $\begin{array}{c}\text { TTA } \\
\text { L }\end{array}$ & $\begin{array}{c}\text { GAA } \\
\text { E }\end{array}$ & $\begin{array}{c}\mathrm{GCT} \\
\mathrm{A}\end{array}$ & $\begin{array}{c}\mathrm{CAC} \\
\mathrm{H}\end{array}$ & $\begin{array}{c}\text { CGT } \\
\text { R }\end{array}$ & $\begin{array}{c}\text { GGC } \\
\text { G }\end{array}$ & $\begin{array}{c}\mathrm{CCA} \\
\mathrm{P}\end{array}$ & $\begin{array}{c}\text { TTT } \\
\text { F }\end{array}$ & $\begin{array}{c}\mathrm{ACA} \\
\mathrm{T}\end{array}$ & $\begin{array}{c}\text { GGT } \\
\text { G }\end{array}$ & $\begin{array}{c}\text { GAA } \\
E\end{array}$ \\
\hline P5a, cont & $\begin{array}{c}\text { TTA } \\
\text { L }\end{array}$ & $\begin{array}{c}\text { GAA } \\
\mathrm{E}\end{array}$ & $\begin{array}{c}\mathrm{GCT} \\
\mathrm{A}\end{array}$ & $\begin{array}{c}\mathrm{CAC} \\
\mathrm{H}\end{array}$ & $\begin{array}{c}\mathrm{CGT} \\
\mathrm{R}\end{array}$ & $\begin{array}{c}\text { GGC } \\
\text { G }\end{array}$ & $\begin{array}{c}\mathrm{CCA} \\
\mathrm{P}\end{array}$ & $\begin{array}{c}\mathrm{TTT} \\
\mathrm{F}\end{array}$ & $\begin{array}{c}\mathrm{ACA} \\
\mathrm{T}\end{array}$ & $\begin{array}{c}\text { GGT } \\
\text { G }\end{array}$ & $\begin{array}{c}\text { GAA } \\
\mathrm{E}\end{array}$ \\
\hline P5b, control & $\begin{array}{c}\text { TTA } \\
\text { L }\end{array}$ & $\begin{array}{c}\text { GAA } \\
\mathrm{E}\end{array}$ & $\begin{array}{c}\text { GCT } \\
\text { A }\end{array}$ & $\begin{array}{c}\mathrm{CAC} \\
\mathrm{H}\end{array}$ & $\begin{array}{c}\text { CGT } \\
\text { R }\end{array}$ & $\begin{array}{c}\text { GAT } \\
\text { D }\end{array}$ & $\begin{array}{c}\mathrm{CCA} \\
\mathrm{P}\end{array}$ & $\begin{array}{c}\text { TTT } \\
\text { F }\end{array}$ & $\begin{array}{c}\mathrm{ACA} \\
\mathrm{T}\end{array}$ & $\begin{array}{c}\text { GGT } \\
\text { G }\end{array}$ & $\begin{array}{c}\text { GAA } \\
\mathrm{E}\end{array}$ \\
\hline P5c, cont & $\begin{array}{c}\text { TTA } \\
\text { L }\end{array}$ & $\begin{array}{c}\text { GAA } \\
\mathrm{E}\end{array}$ & $\begin{array}{c}\text { GCT } \\
\mathrm{A}\end{array}$ & $\begin{array}{c}\text { CAC } \\
\mathrm{H}\end{array}$ & $\begin{array}{c}\text { CGT } \\
\mathrm{R}\end{array}$ & $\begin{array}{c}\text { GAT } \\
\text { D }\end{array}$ & $\begin{array}{c}\mathrm{CCA} \\
\mathrm{P}\end{array}$ & $\begin{array}{c}\text { TTT } \\
\text { F }\end{array}$ & $\begin{array}{c}\mathrm{ACA} \\
\mathrm{T}\end{array}$ & $\begin{array}{c}\text { GGT } \\
\text { G }\end{array}$ & $\begin{array}{c}\text { GAA } \\
E\end{array}$ \\
\hline P5d, control & $\begin{array}{c}\text { TTA } \\
\text { L }\end{array}$ & $\begin{array}{c}\text { GAA } \\
\mathrm{E}\end{array}$ & $\begin{array}{c}\mathrm{GCT} \\
\mathrm{A}\end{array}$ & $\begin{array}{c}\mathrm{CAC} \\
\mathrm{H}\end{array}$ & $\begin{array}{c}\mathrm{CGT} \\
\mathrm{R}\end{array}$ & $\begin{array}{c}\text { GGT } \\
\text { G }\end{array}$ & $\begin{array}{c}\mathrm{CA} A \\
Q\end{array}$ & $\begin{array}{c}\text { TTT } \\
\text { F }\end{array}$ & $\begin{array}{c}\mathrm{ACA} \\
\mathrm{T}\end{array}$ & $\begin{array}{c}\text { GGT } \\
\text { G }\end{array}$ & $\begin{array}{c}\text { GAA } \\
\mathrm{E}\end{array}$ \\
\hline P29a, control & $\begin{array}{c}\text { TTA } \\
\text { L }\end{array}$ & $\begin{array}{c}\text { GAA } \\
E\end{array}$ & $\begin{array}{c}\mathrm{GCT} \\
\mathrm{A}\end{array}$ & $\begin{array}{c}\mathrm{CAC} \\
\mathrm{H}\end{array}$ & $\begin{array}{c}\mathrm{CGT} \\
\mathrm{R}\end{array}$ & $\begin{array}{c}\text { GGT } \\
\text { G }\end{array}$ & $\begin{array}{c}\mathrm{TC} A \\
\mathrm{~S}\end{array}$ & $\begin{array}{c}\text { TTT } \\
\text { F }\end{array}$ & $\begin{array}{c}\mathrm{ACA} \\
\mathrm{T}\end{array}$ & $\begin{array}{c}\text { GGT } \\
\text { G }\end{array}$ & $\begin{array}{c}\text { GAA } \\
E\end{array}$ \\
\hline 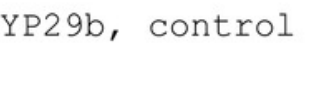 & $\begin{array}{c}\text { TTA } \\
\text { L }\end{array}$ & $\begin{array}{c}\text { GAA } \\
\mathrm{E}\end{array}$ & $\begin{array}{c}\mathrm{GCT} \\
\mathrm{A}\end{array}$ & $\begin{array}{c}\mathrm{CAC} \\
\mathrm{H}\end{array}$ & $\begin{array}{c}\mathrm{CGT} \\
\mathrm{R}\end{array}$ & $\begin{array}{c}\text { GGT } \\
\text { G }\end{array}$ & $\begin{array}{c}\mathrm{TC} A \\
\mathrm{~S}\end{array}$ & $\begin{array}{c}\text { TTT } \\
\text { F }\end{array}$ & $\begin{array}{c}\mathrm{ACA} \\
\mathrm{T}\end{array}$ & $\begin{array}{c}\text { GGT } \\
\text { G }\end{array}$ & $\begin{array}{c}\text { GAA } \\
\mathrm{E}\end{array}$ \\
\hline
\end{tabular}


Figure 4

Schematic representation of the Edit Plasmids for yeast mitochondria.

See MATERIALS \& METHODS for details. Scales for Cas9, and for sgRNA and GFPm were shown in kb.

A.

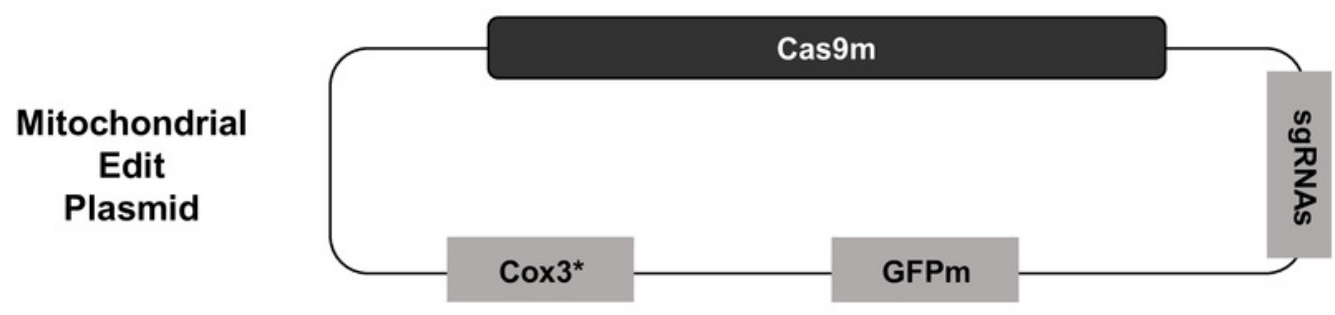

B.

Cas9

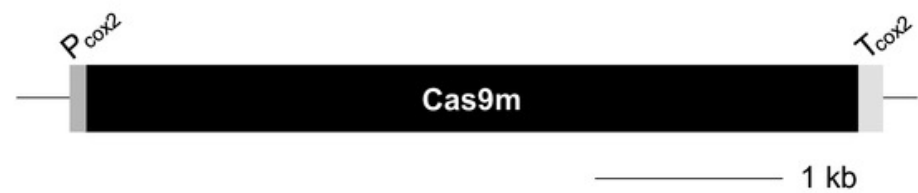

C.

sgRNA

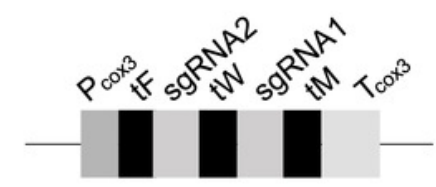

D.

GFP

\section{GFPm}




\section{Figure 5}

\section{Replacement of the mitochondrial genome with donor DNA by Cas9/gRNA}

A: Schematic view of the COX1 genomic region targeted by two gRNAs (arrows) and the donor DNA with GFP gene that is provided by the Edit Plasmid. The recognition sites of primers used for the amplification of the junction regions are indicated (C, F, 11 and 12$)$.

B: PCR analysis of the junction regions of the integrated donor DNA. Left panel: 5' region amplified with C/12 primer set; right panel: 3' region amplified with F/11 primer set. Lanes 1-5: Five control lines with HS6 Edit Plasmid without Cas9 activity; lanes 6-10; Five lines with HS8 Edit Plasmid with Cas9 activity. C: wildtype CUY563 strain; M: $1 \mathrm{~kb}$ plus molecular weight marker (New England Biolabs). Arrows: The size expected from the deduced sequence with integrated donor DNA (C/12 amplicon: 870 bp; F/11 amplicon: 907 bp). DNA fragments separated in lanes 6 and 10 for the both amplicons were isolated for sequence confirmation (see text).

C: The sequence obtained from PCR amplification of the replacement DNA locus in transformed yeast mitochondrial DNA modified by the Edit Plasmid approach. Underlined sequences: wild-type mitochondrial genomic sequences that are not present on the Edit Plasmid. Sequences in bold: Short homologous regions present in the donor DNA (HR1 and HR2) adjacent to gRNA target sites. Sequences with dotted underlining: Modified gRNA target sites present in the donor DNA (altered nucleotides are shown in bold). The codonoptimized GFP coding region is presented in italics. Sequences presented in lower case correspond to primers $\mathrm{C}$ and $\mathrm{F}$ that were used for amplification of the replacement DNA locus. Homologous recombination leading to DNA replacement occurred without causing any sequence changes either in the replacement DNA nor in the surrounding wild-type mitochondrial DNA. 
A.

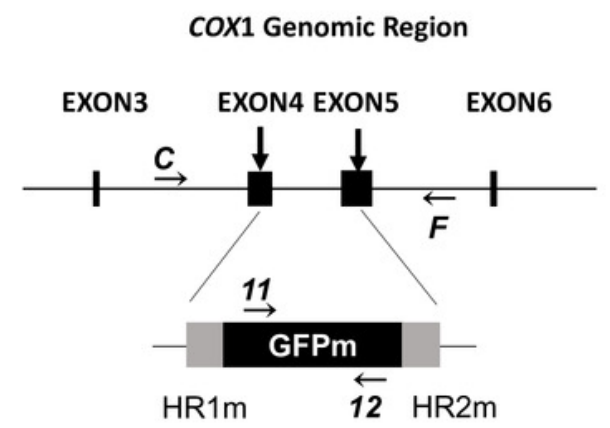

B.

Primers C \& 12

\section{Primers $F \& 11$}

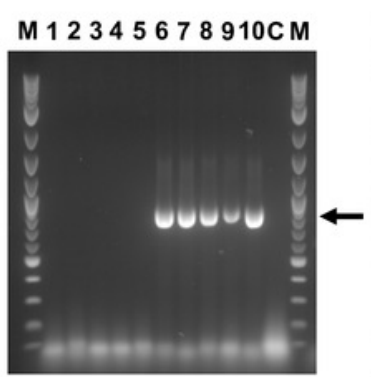

Cas9
M $12345678910 \mathrm{CM}$

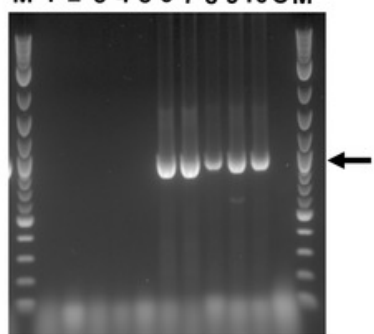

Cas9 - $\quad+$
C.

ctattcaggcacattcaggaccTAGTGTAGATTTAGCAATTTTTGCAT TACATTTAACATCAATTTCATCATTATTAGGTGCTATTAATTTCATTG TAACAACATTAAATATGAGAACAAATGGTATGACAATGCATAAATTAC CATTATTTGTATGATCAATTTTCATTACAGCGTTCTTATTATTATTAT CATTACCTGTATTATCTGCTGGTATTACAATGTTATTATTAGATAGAA ACTTCAATACTTCATTTTCGGAGTTTCTGGTGGAGGTGGTGGAATGA CACATTTAGAAAGAAGTAGACAAATGTCAAAAGGTGAAGAATTATTCA CTGGAGTAGTACCTATCTTAGTAGAATTAGATGGTGATGTAAATGGTC ATAAATTCTCAGTATCAGGTGAAGGTGAAGGTGATGCTACATATGGTA AATTAACATTAAAATTCATCTGTACAACAGGTAAATTACCTGTACCTT GACCTACATTAGTAACAACATTCGGATATGGAGTACAATGTTTCGCAA GATATCCTGATCATATGAAACAACATGATTTCTTCAAATCAGCAATGC CTGAAGGTTACGTACAAGAAAGAACAATCTTCTTCAAAGATGATGGTA ATTATAAAACAAGAGCTGAAGTAAAATTCGAAGGTGATACATTAGTAA ATAGAATCGAGTTAAAAGGTATCGATTTCAAAGAAGATGGTAATATCT TAGGTCATAAATTAGAATATAATTATAATTCACATAATGTATATATCA TGGCTGATAAACAAAAAAATGGTATCAAAGTAAATTTCAAAATCAGAC ATAATATCGAAGACGGTTCAGTACAATTAGCAGATCATTATCAACAAA ATACACCTATCGGTGATGGTCCTGTATTATTACCTGATAATCATTACT TAAGTACACAATCAGCTTTATCAAAAGATCCTAATGAAAAAAGAGATC ATATGGTATTATTAGAATTTGTAACAGCTGCTGGTATCACACATGGTA TGGATGAATTATATAAATAACAACAGGAATTAAAATTTTCTCATGATT AATAAATCCCTTTAGCAAGGATAAAAATAAAAATAAAAATAAAAAGTT GATCAGAAATTATCAAAAAATAAATAATAATAATATAATAAAAACATA TTTAAATAATAATAATATAATTATAATAAATATATATAAAGGTAATTT ATATGATATTTATCCAAGATCAAATAGAAATTATATTCAACCAAATAA TATTAATAAAGAATTAGTAGTATATGGTTATAATTTAgaatcttgtgt tggtatacctct 


\section{Figure 6}

Characterization of Edit Plasmids rescued from yeast mitochondrial transgenic cells.

A \& B: Restriction analysis of rescued Edit Plasmids. Lane 1, the original Edit Plasmid DNA, Lane 2 - 6, rescued Edit Plasmids from yeast cells. Plasmids were digested with Ncol and Clal (A) or Ncol and Pstl (B), and separated by $1.0 \%$ agarose gel electrophoresis.

C: Semi-quantitative PCR assay of the Edit Plasmid DNA (HS8) after the cross with the wild-type rho ${ }^{+}$strain. Lane 1, first overnight culture; lane 2, second; lane 3, third; and lane 4, fourth overnight culture. M: 1 kb plus molecular weight marker (New England Biolabs).

A.

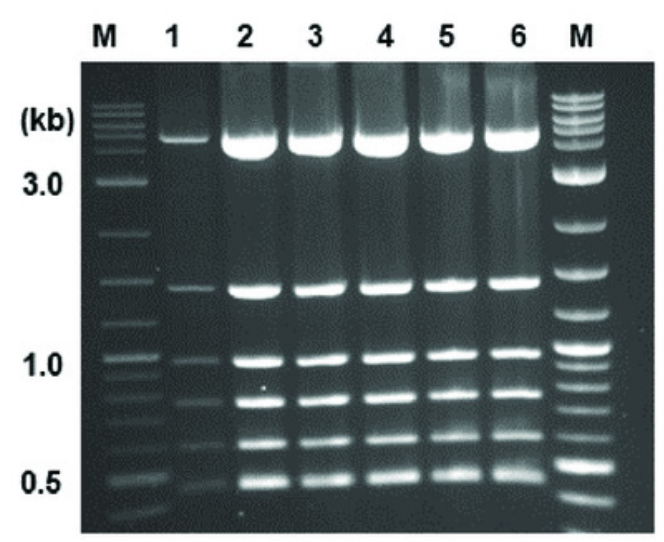

B.

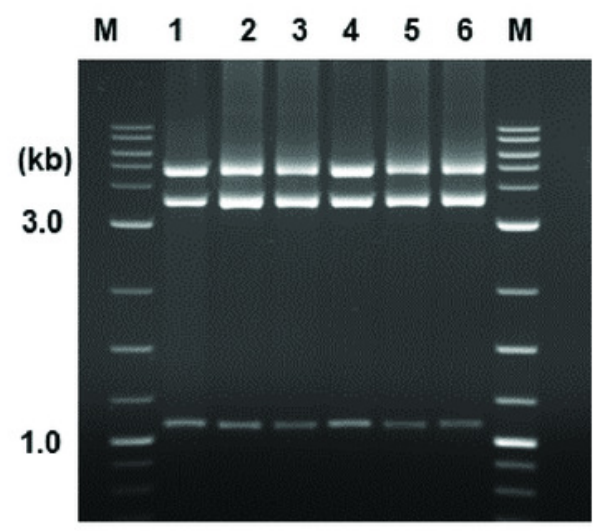

c.

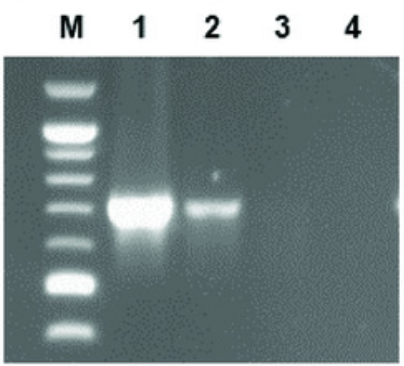


Table $\mathbf{1}$ (on next page)

List of Edit Plasmids for Organelle Transformation 


\begin{tabular}{|c|c|c|c|c|c|c|}
\hline $\begin{array}{c}\text { Edit } \\
\text { Plasmid }\end{array}$ & Organism & Organelle & $\begin{array}{c}\text { Expr Cassette } \\
\mathbf{1}^{*} \\
\text { Promoter for } \\
\text { Cas9 }\end{array}$ & $\begin{array}{c}\text { Expr Cassette 2 } \\
\text { Guide RNA }\end{array}$ & Dector \\
\hline YP5 & Chlamydomonas & chloroplast & $p s a A$ & N/A & N/A & packbone \\
\hline YP11 & Chlamydomonas & chloroplast & $p s a A$ & sgRNA1c \& 2c & N/A & pUC19 \\
\hline YP12 & Chlamydomonas & chloroplast & $p s a A$ & sgRNA3c \& 4c & N/A & pUC19 \\
\hline YP13 & Chlamydomonas & chloroplast & $p s a A$ & sgRNA1c \& 2c & HR1c:GFPc:HR2c & pUC19 \\
\hline YP14 & Chlamydomonas & chloroplast & $p s a A$ & sgRNA3c \& 4c & HR3c:GFPc:HR4c & pUC19 \\
\hline YP6 & Chlamydomonas & chloroplast & $p s b D$ & N/A & N/A & pUC19 \\
\hline YP19 & Chlamydomonas & chloroplast & $p s b D$ & sgRNA1c \& 2c & N/A & pUC19 \\
\hline YP20 & Chlamydomonas & chloroplast & $p s b D$ & sgRNA3c \& 4c & N/A & pUC19 \\
\hline YP21 & Chlamydomonas & chloroplast & $p s b D$ & sgRNA1c \& 2c & HR1c:GFPc:HR2c & pUC19 \\
\hline YP22 & Chlamydomonas & chloroplast & $p s b D$ & sgRNA3c \& 4c & HR3c:GFPc:HR4c & pUC19 \\
\hline YP23 & Chlamydomonas & chloroplast & N/A & sgRNA1c \& 2c & HR1c:GFPc:HR2c & pUC19 \\
\hline YP24 & Chlamydomonas & chloroplast & N/A & sgRNA3c \& 4c & HR3c:GFPc:HR4c & pUC19 \\
\hline YP29 & Chlamydomonas & chloroplast & N/A & sgRNA1c \& 2c & HR1c:GFPc:HR2c & pBR322 \\
\hline YP31 & Chlamydomonas & chloroplast & $p s a A$ & sgRNA1c \& 2c & N/A & pBR322 \\
\hline YP33 & Chlamydomonas & chloroplast & $p s b D$ & sgRNA1c \& 2c & N/A & pBR322 \\
\hline HS6 & Saccharomyces & mitochondria & N/A & sgRNA1m \& 2m & HR1m:GFPm:HR2m & pBR322 \\
\hline HS8 & Saccharomyces & mitochondria & COX2 & sgRNA1m \& 2m & HR1m:GFPm:HR2m & pBR322 \\
\hline
\end{tabular}


Table 2 (on next page)

Yeast strains used in this study. 
1

\begin{tabular}{|c|c|c|}
\hline Strain & Genotype & Source \\
\hline $\mathrm{MCC} 109 \rho^{0}$ & MAT $\alpha$ ade 2 ura3 karl-1 $\left[\rho^{0}\right]$ & Costanzo \& Fox (1993) \\
\hline MCC125 & MATa lys $2[\operatorname{cox} 3-10 \rho+]$ & Costanzo \& Fox (1993) \\
\hline CUY563 & MATa ade2-101 ade3-24 leu2-3,112 ura3-52 $\left[\rho^{+}\right]$ & Roberg et al. (1999) \\
\hline NB80 & $\begin{array}{l}\text { MATa lys2 leu2-3,112 ura3-52 his3 } 3 \text { HinDIII } \\
\text { arg8::hisG }\left[\rho^{+}\right]\end{array}$ & Bonnefoy \& Fox (2000) \\
\hline
\end{tabular}

2

3

4 


\section{Table 3(on next page)}

Summary of Cas9/gRNA induced integration of donor DNA into organelle genomes

Numbers in parentheses: Independent transgenic events tested in Chlamydomonas chloroplasts and biological replications tested in yeast mitochondria 


\begin{tabular}{|c|c|c|c|c|c|c|c|c|}
\hline Construct & Organism & Organelle & Cas9 & $\begin{array}{c}\text { Cas9 } \\
\text { Promoter }\end{array}$ & sgRNA & $\begin{array}{c}\text { Donor } \\
\text { DNA }\end{array}$ & Vector & $\begin{array}{l}\text { Donor DNA } \\
\text { Integration* }\end{array}$ \\
\hline YP13 & Chlamydomonas & chloroplast & + & psaA & $1 \mathrm{c} / 2 \mathrm{c}$ & + & pUC19 & $+(2 / 20)$ \\
\hline YP14 & Chlamydomonas & chloroplast & + & $p s a A$ & $3 c / 4 c$ & + & pUC19 & $\begin{array}{ll}- & (0 / 17)\end{array}$ \\
\hline YP21 & Chlamydomonas & chloroplast & + & $p s b D$ & $1 \mathrm{c} / 2 \mathrm{c}$ & + & pUC19 & - $(\mathbf{0} / \mathbf{1 0})$ \\
\hline YP22 & Chlamydomonas & chloroplast & + & $p s b D$ & $3 c / 4 c$ & + & pUC19 & $-\quad(0 / 10)$ \\
\hline YP23 & Chlamydomonas & chloroplast & - & - & $1 \mathrm{c} / 2 \mathrm{c}$ & + & pUC19 & $-\quad(0 / 16)$ \\
\hline YP24 & Chlamydomonas & chloroplast & - & - & $3 c / 4 c$ & + & pUC19 & $-\quad(0 / 16)$ \\
\hline HS6 & Saccharomyces & mitochondria & - & - & $1 \mathrm{~m} / 2 \mathrm{~m}$ & + & pBR322 & - $(\mathbf{0} / \mathbf{1 5})$ \\
\hline HS8 & Saccharomyces & mitochondria & + & COX2 & $1 \mathrm{~m} / 2 \mathrm{~m}$ & + & pBR322 & $+(15 / 15)$ \\
\hline
\end{tabular}




\section{Table 4 (on next page)}

Summary of DNA alterations at sgRNA2c site in Chlamydomonas chloroplasts.

SNP frequency was measured at the Avall site in chloroplast transformants with Edit Plasmids carrying different Cas9 promoters ( $p s a A, p s b D$ or none), vector backbone, and with and without the guide RNA (sgRNA2c) or donor DNA. SNP frequency was deduced by the number of SNP detected per number of amplicon clones analyzed (see MATERIALS \& METHODS). 
1

2

\begin{tabular}{|c|c|c|c|c|c|c|c|c|}
\hline Experiment Type & Construct & Cas9 & $\begin{array}{c}\text { Cas9 } \\
\text { Promoter }\end{array}$ & $\begin{array}{c}\text { SgRNA } \\
2 \mathrm{c}\end{array}$ & Donor & Vector & $\begin{array}{l}\text { SNP } \\
\text { Freq. }\end{array}$ & $\%$ \\
\hline \multirow{5}{*}{ Test } & YP11 & + & $p s a A$ & + & - & pUC19 & $2 / 48$ & \\
\hline & YP31 & + & psaA & + & - & pBR322 & $2 / 18$ & \\
\hline & Total: YP11+LP31 & + & $p s a A$ & + & - & & $4 / 66$ & 6.06 \\
\hline & YP33 & + & $p s b D$ & + & - & pBR322 & $0 / 24$ & \\
\hline & $\begin{array}{l}\text { Total: } \\
\text { YP11+LP3+YP33 }\end{array}$ & + & & + & - & & $4 / 90$ & 4.44 \\
\hline \multirow{3}{*}{ Negative Control } & YP5 & + & $p s a A$ & - & - & pUC19 & $5 / 49$ & \\
\hline & YP29 & + & - & + & + & pBR322 & $2 / 51$ & \\
\hline & Total, YP5+YP29 & + & & & & & $7 / 100$ & 7.00 \\
\hline
\end{tabular}

3

4

5 